\title{
Chapter 9 \\ The Labor Market Effects of Skill-Biased Technological Change in Malaysia
}

\author{
Mohamed A. Marouani and Björn Nilsson
}

\begin{abstract}
During the last half-century, the evolution of educational attainment in Malaysia has been spectacular, and current enrollment rates suggest this progression will continue. Such a transformation of the labor skill composition should bring about macroeconomic effects such as wage compression, sectoral shifts, and high skill unemployment, unless compensatory mechanisms exist. Relying on decomposition techniques, we argue that skill-biased technological change (SBTC) occurred in Malaysia in recent years and permitted unemployment figures to remain low and skill premia not to sink. We also develop a dynamic general equilibrium model, simulating the absence of SBTC and limiting the number of admissions to higher education. The results are fed to a microsimulation module. They show that the reduction in wage inequalities could have been substantially more important had SBTC not been present. Furthermore, they suggest that the open-door higher education policy has contributed heavily to a reduction in wage inequalities.
\end{abstract}

\footnotetext{
Reprinted from Economic Modelling, Vol 57, Mohamed A. Marouani, Björn Nilsson. The labor market effects of skill-biased technological change in Malaysia, pages 55-75, Copyright (2016), with permission from Elsevier. This paper is one of the background papers for the report titled "Developing Skills for Innovation and High Income Economy in Malaysia." The authors thank Mr. Amir Omar, Director of Institute of Labor Market Information and Analysis (ILMIA), and his excellent team in the Ministry of Human Resources of Malaysia for their hard work throughout this engagement. Thank you also to the Department of Statistics of Malaysia for assistance with all data-related matters, other government agencies represented in the steering committee for their guidance throughout consultations, and all stakeholders (employers, union representatives, and business associations) for their valuable contributions throughout the drafting of this paper. The findings, conclusions, and views expressed in this paper are entirely those of the authors and should not be attributed to the World Bank, its executive directors, and the countries they represent.
}

M. A. Marouani $(\bowtie)$

Université Paris 1 Panthéon-Sorbonne, DIAL and ERF, Nogent sur Marne, France

e-mail: marouani@univ-paris1.fr

B. Nilsson

DIAL, Université Paris-Dauphine, Paris, France

e-mail: nilsson@dial.prd.fr 
Keywords Skills acquisition · CGE · Education and the labor market · Inputoutput $\cdot$ Technological change

JEL Classification E17 $\cdot$ I28 $\cdot$ E24 $\cdot \mathrm{H} 52 \cdot \mathrm{O} 30 \cdot \mathrm{O} 53$

\section{Introduction}

Many countries have experienced sharp increases of enrollment in tertiary educa$\operatorname{tion}^{1}$ in the last decades, with varying economic and social outcomes. The massification of higher education is sometimes a deliberate policy tool and sometimes the result of a laissez-faire attitude from policy-makers facing increased demand for higher education. Should increased educational attainment, especially at the tertiary level, always be encouraged? Will an exogenous increase in the numbers of tertiary educated be followed by increased demand from firms, in some sort of skills-driven structural change? What is the likely impact of increased enrollment on returns to education and on graduate unemployment?

In the presence of an increasing supply of educated labor, labor market outcomes of educated workers are conditional on the evolution of their demand. An underlying issue here is that of the substitutability between labor categories with different educational attainment. Several authors argue (Goldin and Katz 1998; Caselli and Coleman 2006) that this substitutability is imperfect, some countries being better at taking advantage of their skilled workers than others. Caselli and Coleman (2006) argue that countries more abundant in skilled labor will choose technologies best suited to skilled labor, while countries abundant in unskilled labor will choose technologies best suited to unskilled labor, barriers to technology adoption explaining why some countries are unable to make efficient use of their skilled labor. While it would be a stretch to argue that there is consensus on the issue, skill-biased technological change (SBTC) has often been suggested as one of the drivers behind simultaneously rising wage premia and share of skilled workers in the United States (Autor et al. 1998). Empirical evidence has also suggested this is the case in other developed countries. There is some scarce evidence of skill-biased technological change in developing countries (Berman and Machin 2000), but not many countryspecific studies have been carried out. To our knowledge, no one has attempted to study skill-biased technical change in Malaysia. We choose to study Malaysia since its spectacular increase in educational attainment has not been accompanied by falling wage premia of tertiary graduates.

\footnotetext{
${ }^{1}$ Gross enrollment rates in tertiary education for upper- to middle-income countries have increased from $8 \%$ to $30 \%$ in the period 1990-2010. In Malaysia, they have increased from $7 \%$ to $37 \%$ during the same period.
} 
The other major labor market adjustment to rising relative quantities of skilled labor is increased unemployment of skilled workers. High public investment in education has been shown to increase unemployment in some contexts, high-skilled unemployment sometimes even being higher than that of low and medium skilled. ${ }^{2}$ The Middle East and North Africa (MENA) region, which has heavily invested in education over four decades, ${ }^{3}$ serves as a good example of an unsuccessful absorption of young graduates into the labor market (Marouani 2010; Marouani and Robalino 2012). However, not only do employment figures matter in their own, it is also important to consider the type of employment facing young graduates. The suggested theoretical links between educational accumulation and growth have sometimes been hard to demonstrate empirically. The arguments put forward range from quality of education to a misallocation problem. Pritchett (1996) argues that one of the reasons education has not been positive for growth is due to inefficient use of graduates, who end up in low-productivity sectors such as state-owned enterprises. This could particularly be the case in those contexts where the state acts as a de facto employer of last resort.

An increase in educational attainment implies two things: first of all, a steadily increasing demand for education. Second is that this increased demand has been met by an increased supply, either from the government or from private actors. The question is whether this expansion of supply is a deliberate policy choice or just an expansion to cover what is called the social demand for education. Blaug (1967) reflects on this in an early paper, arguing that the spontaneous increase of educational supply faced with increasing demand could find its origin in a belief that something akin to Say's Law operates in the market for professional manpower, i.e., that supply of skilled labor will create its own demand. Thus, planners need not fear increasing educational supply in the sense that labor market constraints are unlikely to operate. The topic is however difficult to apprehend: first of all, without a precise picture of the demand for education, it is impossible to know whether supply has been a constraint or not in the evolution of educational attainment. That is, have all those who wished to go into tertiary education been able to do so? If this is the case, have there not been shadow costs associated with the increase, such as increasing rates of exam failure?

Methodological differences and accuracy problems render educational projection exercises notoriously difficult. Blaug (1967) describes the three major methods of forecasting skill requirements, all relying on a number of assumptions and restrictions. Firstly, manpower forecasts attempt to project sectoral quantities of skilled labor needed to attain certain GDP targets. They rely on labor-output coefficients and education-occupation matrices that are difficult to estimate. Secondly, social demand methods attempt to project the private demand for education, given fixed

\footnotetext{
${ }^{2}$ This is the case for Morocco (Kabbani and Kothari 2005).

${ }^{3}$ MENA countries spent around 5\% of GDP on education over the period. At similar levels of educational attainment, the MENA region boasts significantly higher unemployment rates of graduates (World Bank 2008) than other emerging regions. The equivalent spending figure for two groups of Asian and Latin American countries, respectively, is around 3\%.
} 
direct and indirect costs. Finally, rate of return methods, which are perhaps the most well-known methods used by educational planners. Ceteris paribus, the evolution of the rate of return to a certain skill gives an indication of the value the market places on the skill. If this rate is increasing, it means that employers' demand for this particular skill is rising faster than its supply. Rates of return could thus be used by planners as an indicator of skill gaps to be filled. All three methods have their own weaknesses. In particular, manpower planning has been largely abandoned in academia since its less than desirable track record (Blaug and Ahamad 1974).

Glytsos (1990) argues that severe imbalances between supply and demand for certain skills have been a feature of developed and developing countries alike during the 1970s and 1980s, which tends to confirm the mediocre track record of educational planning before and during this period. ${ }^{4}$ Interestingly, he argues that these imbalances have not only been a feature of countries with open enrollment policies, i.e., where quantitative restrictions on the number of students do not exist (perhaps due to social concerns such as equality of access), but also in those countries where admission controls are a fact. We contend that a general equilibrium approach to educational planning permits to overcome some of the most obvious drawbacks of the main methods used to project or forecast educational needs. Notably, manpower forecasts and social demand estimates both consider educational dynamics from one side - that of demand in the case of manpower forecasts and that of supply in the case of the "social" demand for education. The evolution, however, is determined jointly by supply and demand factors. Furthermore, the demand and supplies are derived using a constant price hypothesis. A general equilibrium approach permits prices to vary according to relative supply and demand but also according to productivity and international demand trend differentials. Also, while manpower forecasting and social demand gives target figures, our model permits a simulation of the labor market impacts of educational policy designed to achieve such target figures. Our focus in doing this is on wage premia and unemployment figures.

The higher education policy of the Malaysian government stems from a willingness to increase quickly and significantly the share of skilled labor in the economy (40\% enrollment in higher education is a policy target [Guan 2012]). This article aims to study the impact of this policy on labor market and income distribution outcomes. As explained above, similar policies have proven inefficient in other contexts. Relying on decomposition techniques, we argue that it is thanks to skill-biased technological change that expected wage premia have been relatively stable in Malaysia, maintaining a strong social demand for higher education, thereby perpetuating the educational dynamics. We also develop a dynamic general equilibrium model in which we run a retrospective simulation, looking at how unemployment and wages would have reacted had skill-biased technological change not been prevalent. Furthermore, we simulate the effects of a restriction in the supply of educa-

\footnotetext{
${ }^{4} \mathrm{An}$ alternative to educational planning could have been to let the market regulate supply and demand of educational services, requiring that the total cost of educational services be covered by students. Such a system would however have obvious drawbacks in terms of equality of opportunities.
} 
tion to understand the impact of recent educational policy in Malaysia. The results are fed to a microsimulation module, addressing distributional concerns.

The rest of the article is organized as follows. Section 2 describes the Malaysian educational expansion of the last two decades and the accompanying labor market adjustments. Section 3 lays out the various blocks of the model, with a particular emphasis on the accumulation of skilled labor. Section 4 presents the data and the calibration of the model. Section 5 lays out the microsimulation module used to analyze wage inequalities. Section 6 presents the simulations and their results. Section 7 concludes.

\section{The Evolution of Malaysians' Educational Attainment}

Educational attainment in Malaysia has increased remarkably in the last two decades. The two main features of this increase are a big drop in the number of Malaysians with a primary education or less, coupled with a strong increase in the number of secondary and tertiary educated. The second feature has been a clear policy target for the Malaysian government, desirous to see enrollment rates in higher education of $40 \%$ by 2010 (Guan 2012). The increase in supply of higher education has taken two forms. Firstly, private universities were established in the 1990s (the number of private universities in Malaysia increased from 0 in 1990 to 21 in 2009). Secondly, the number of public universities increased from 7 in 1990 to 20 in 2009. The expansion of tertiary education has not only been a general higher education phenomenon. The creation of community colleges and the expansion of polytechnic establishments have increased enrollment over the last two decades and show how the share of highly educated Malaysians has risen sharply and continuously since the early 1990s (Fig. 9.1).

Standard economic theory holds that this important shift in relative quantities should be accompanied - ceteris paribus - by a decrease in the wage premium for educated employees. Figure 9.2 shows that average wages in Malaysia have remained relatively constant between 2007 and 2010. ${ }^{5}$ An indicator of wage premia can be obtained from studies on returns to education in Malaysia. Chung (2003) looks at the returns to education in Malaysia using a dataset from 1997 and finds that the returns to secondary education are $12 \%$ and $15.7 \%$ for male and female, respectively, while the returns to higher education are $18.1 \%$ and $16.4 \%$. Kenayathulla (2013) recently revisited those figures, using Household Income Survey figures from 2007. She finds evidence of a return to secondary education of $16.5 \%$ and $27.2 \%$ for males and females, the corresponding figures for higher education being $15.5 \%$ and $16.1 \%$. This anecdotal evidence thus suggests the presence of some mechanism favorable to skilled labor during the last two decades in Malaysia.

\footnotetext{
${ }^{5}$ Unfortunately we do not have wage data from before 2007.
} 


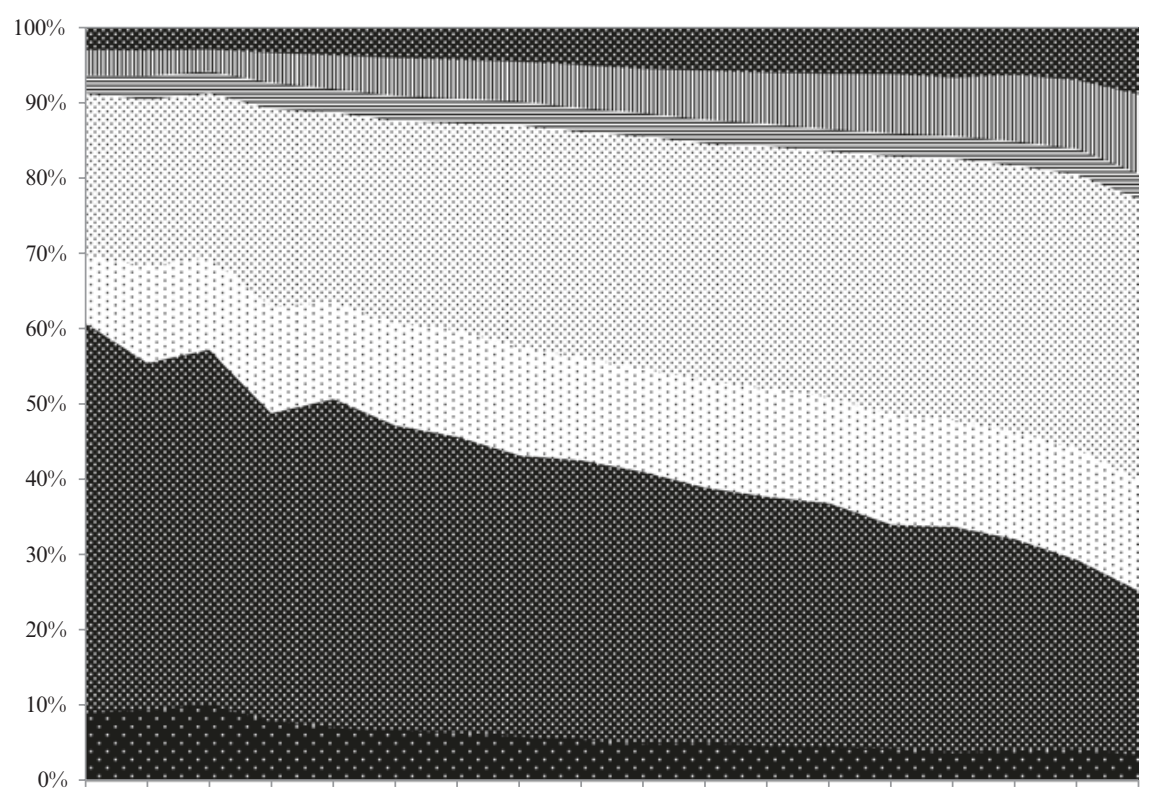

199019921993199519961997199819992000200120022003200420052006200720082010

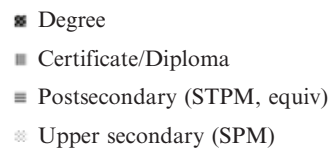

Fig. 9.1 Educational distribution of the Malaysian labor force, 15-64 years old. (Source: Labor Force Surveys from 1990 to 2010). Note: N/A corresponds to individuals who never went to school

Fully noting that the concept of skill is a multidimensional and complex one, we choose to define skilled labor categories in terms of various levels of education and fields of study. We hereby ignore any skills acquired in the workplace or any skill endowments independent of schooling.

From Fig. 9.1, it can be seen that the share of educated Malaysians in the workforce has risen steadily since the early 1990s. The situation is analogous to the US one in the 1980s-1990s and merits a closer look. At the aggregate level, a standard CES production function yields the following relative wage when profits are maximized (Sanders and ter Weel 2000):

$$
\omega=\frac{w_{S}}{w_{U}}=\left[\frac{\theta_{S}}{\theta_{U}}\right]^{\rho}\left[\frac{L_{U}}{L_{S}}\right]^{1-\rho}
$$

where $\mathrm{w}_{\mathrm{S}}, w_{U}$ and $\mathrm{L}_{\mathrm{S}}, \mathrm{L}_{\mathrm{U}}$ are wages and employment of skilled and unskilled workers, respectively, $\theta_{S}$ and $\theta_{U}$ are the productivity parameters associated with 


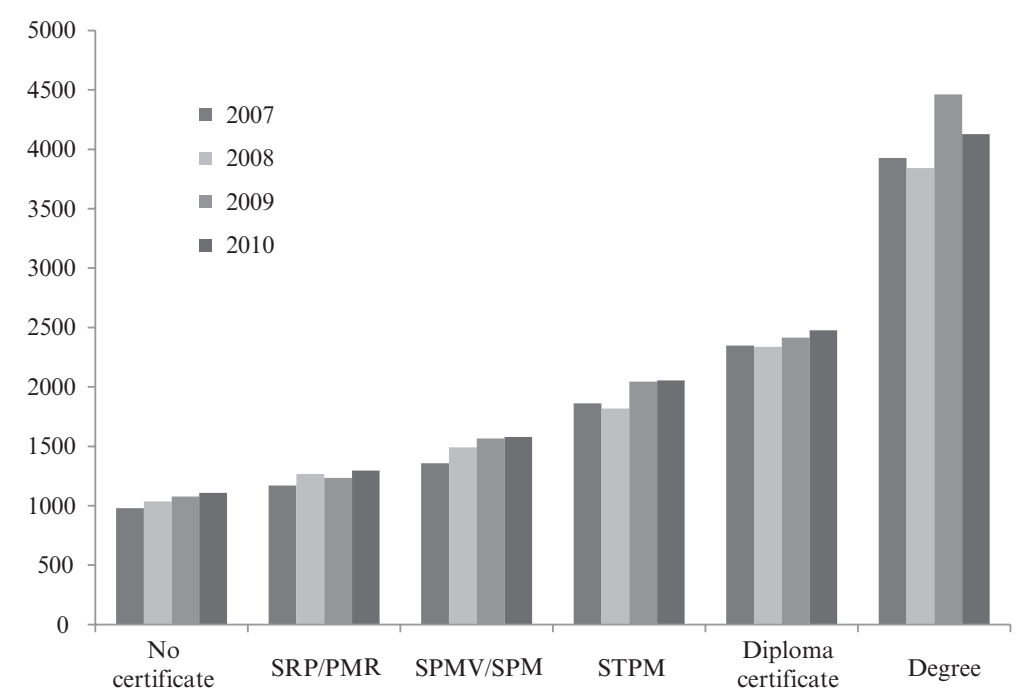

Fig. 9.2 Average wage by educational attainment, Malaysian employees (RM). (Source: Labor Force Surveys from 2007 to 2010. Wages represent average nominal wages for 15-64-year-old Malaysian out-of-school wage earners)

skilled and unskilled labor, and $\frac{1}{1-\rho}$ is the elasticity of substitution between productivity-corrected labor bundles. It thus becomes apparent that in presence of increasing relative quantities of skilled workers, a decrease in the wage premium of skilled labor can only be avoided if there is an increase in the relative technological efficiency of this labor category. Figures 9.1 and 9.2 would thus suffice to argue for the presence of skill-biased technological change in Malaysia. However, when one considers a sectorally disaggregated production structure, it becomes apparent that sector-biased technological change - if favoring skill-intensive sectors - might in the same fashion increase the demand for skills, counteracting the supply shift and ensuring stable wage premia. Several authors have used translog cost functions to investigate the presence of skill-biased technological change (Machin and Reenen 1998; Autor et al. 1998; Sanders and ter Weel 2000). Since we were unable to find R\&D data at the industry level in Malaysia, we do not follow this approach. Table 9.3 however shows the evolution of industry labor shares and industry-skilled labor concentrations between 2007 and 2010. Decomposing the aggregate change in the proportion of skilled labor into changes between and within sectors (Machin and 
Table 9.1 Labor force in 1990, by highest certificate obtained

\begin{tabular}{l|l|l|l}
\hline Degree & Employed (\%) & Unemployed (\%) & Total labor force (\%) \\
\hline SRP/PMR & 92.7 & 7.3 & 100.0 \\
\hline SPMV & 89.6 & 10.4 & 100.0 \\
\hline SPM & 93.4 & 6.6 & 100.0 \\
\hline STPM & 93.2 & 6.8 & 100.0 \\
\hline Diploma & 97.5 & 2.5 & 100.0 \\
\hline Degree & 97.9 & 2.1 & 100.0 \\
\hline Not applicable & 97.9 & 2.1 & 100.0 \\
\hline No certificate & 96.2 & 3.8 & 100.0 \\
\hline Missing & 100.0 & 0.0 & 100.0 \\
\hline Total & 95.5 & 4.5 & 100.0 \\
\hline
\end{tabular}

Source: 1990 Labor Force Survey

Table 9.2 Labor force in 2011, by highest certificate obtained

\begin{tabular}{l|l|l|l}
\hline Degree & Employed (\%) & Unemployed (\%) & Total labor force (\%) \\
\hline UPSR or similar & 97.5 & 2.5 & 100.0 \\
\hline PMR/SPR or similar & 97.3 & 2.7 & 100.0 \\
\hline SPM or similar & 96.7 & 3.3 & 100.0 \\
\hline STPM or similar & 96.2 & 3.8 & 100.0 \\
\hline Certificate & 94.9 & 5.1 & 100.0 \\
\hline Diploma & 96.5 & 3.5 & 100.0 \\
\hline Tertiary degree & 96.4 & 3.6 & 100.0 \\
\hline No degree & 98.4 & 1.6 & 100.0 \\
\hline Not applicable & 95.8 & 4.2 & 100.0 \\
\hline Total & 96.9 & 3.1 & 100.0 \\
\hline
\end{tabular}

Source: 2011 Labor Force Survey

Reenen 1998; Berman et al. 1998) ${ }^{6}$ for Malaysia shows that the lion's share of the upskilling has occurred within industries (74\%) rather than between industries (26\%), which leads us to believe that the simultaneous stability of wage premia and high increase of the skill share are associated with skill-biased technical change, rather than a structural change due to a Stolper-Samuelson effect, or any other industry-biased demand alteration. The same analysis was carried out for a period of 20 years (1990-2010) at the three-digit industry level, with the within component of upskilling being equal to $73 \%$. An analysis of labor at the firm level, using the 2005 and 2010 rounds of the Economic Census, is carried out in the World Bank (forthcoming) and shows that significant upskilling has occurred at the firm level.

Instead of affecting wages, which might be prevented from falling by union activities, it could be that the labor market adjusts to the increase of skilled workers

\footnotetext{
${ }^{6}$ Following these authors, we decompose the change in the aggregate skill proportion into two components: $\Delta S=\sum S_{i} \bar{E}_{i}+\sum \bar{S}_{i} E_{i}$, where $S_{\mathrm{i}}$ is the share of skilled labor at the industry level and $E_{\mathrm{i}}$ the employment share of each industry in total employment.
} 
through an increase in unemployment. Looking at unemployment, we see that unemployment of individuals with postsecondary education has only increased slightly (Tables 9.1 and 9.2). Degree holders have seen their rate of unemployment increase from $2.1 \%$ to $3.6 \%$. The unemployment rate of diploma holders has risen from $2.5 \%$ to $3.5 \%$. The certificates category, which did not exist in 1990 and corresponds to low-level diplomas representing 1 year of postsecondary education, is the most severely affected category by unemployment with a $5 \%$ unemployment rate in 2011.

The variations are thus minor, relative to the increases in quantities: between 1990 and 2011, the labor force increased by $81 \%$. At the same time, the number of diploma holders increased by $400 \%$ and that of degree holders by $654 \%$. The possibility of unemployment increases as the primary mechanism preserving wage premia facing constant demand thus seems highly unlikely (Table 9.3).

Table 9.3 Evolution of industry labor shares and proportion of skilled labor by industry, 2007-2010

\begin{tabular}{l|c|c}
\hline Industry & $\Delta$ (labor share) $)$ & $\begin{array}{l}\Delta \text { (skills } \\
\text { proportion) })\end{array}$ \\
\hline Agriculture & -4 & 203 \\
\hline Oil and gas & 67 & 54 \\
\hline Manufacturing food, beverages, tobacco & 38 & 127 \\
\hline Manufacturing textile & -26 & 92 \\
\hline Manufacturing wood & -22 & 33 \\
\hline Manufacturing paper and furniture & -3 & 13 \\
\hline Manufacturing chemicals rubber & 6 & -3 \\
\hline Metals, machinery, equipment NEC & -6 & 18 \\
\hline Electronics and electrical & -11 & 11 \\
\hline Manufacturing and transport equipment & -15 & 48 \\
\hline Utilities & 4 & 34 \\
\hline Construction & 8 & 16 \\
\hline Wholesale and retail & 18 & 20 \\
\hline Accommodation and restaurants & 15 & 4 \\
\hline Logistics & 14 & 13 \\
\hline Post and telecoms & 22 & 11 \\
\hline Finance & 11 & -2 \\
\hline Real estate & 58 & 34 \\
\hline Business services & -3 & 7 \\
\hline Education & 35 & 8 \\
\hline Health & 32 & 9 \\
\hline Other services & -2 & 63 \\
\hline Public administration & 20 & 32 \\
\hline Soure: Lat Force Surveys fro & &
\end{tabular}

Source: Labor Force Surveys from 2007 to 2010 


\section{The Model}

We develop a dynamic general equilibrium model with a detailed description of the labor market, taking into account jobs across sectors and workers with different ages (youth and non-youth) and levels of education (Marouani and Robalino 2012). The model also formalizes educational choices and immigration flows. The following section will lay out the main equations of the model. The economy is disaggregated into 23 sectors, with 21 different factors of production, corresponding to labor of 20 different skill types, and physical capital. At the sectoral level, value added is a nested constant elasticity of substitution (CES) function of capital and labor. The labor aggregate is disaggregated into three bundles: a high-skilled labor bundle (HS), a medium-skilled labor bundle (MS), and a low-skilled labor bundle (LS). The nested production structure allows for differentiated elasticities of substitution between various factors of production.

\subsection{The Production Structure}

Value added is a constant elasticity of substitution function of capital and a labor aggregate $\mathrm{L}^{7}$ :

$$
X_{t}=\left(\alpha_{K} K_{t}^{1-\frac{1}{\sigma_{1}}}+\alpha_{L} L_{t}^{1-\frac{1}{\sigma_{1}}}\right)^{\frac{1}{1-\frac{1}{\sigma_{1}}}}
$$

The first-order conditions imply the following factor demands:

$$
\begin{aligned}
& K_{t}=X_{t}\left(\frac{\alpha_{K} P V A_{t}}{R_{t}}\right)^{\sigma_{1}} \\
& L_{t}=X_{t}\left(\frac{\alpha_{L} P V A_{t}}{P L_{t}}\right)^{\sigma_{1}}
\end{aligned}
$$

At the following nest, $\mathrm{L}$ is decomposed into three bundles containing workers with academic degrees, vocationally trained, and secondary school graduates or lower:

\footnotetext{
${ }^{7}$ Sectoral indices have been omitted in this section for readability.
} 


$$
L_{t}=A_{t}\left(\alpha_{H S} H S_{t}^{1-\frac{1}{\sigma_{2}}}+\alpha_{M S} M S_{t}^{1-\frac{1}{\sigma_{2}}}+\alpha_{L S} L S_{t}^{1-\frac{1}{\sigma_{2}}}\right)^{\frac{1}{1-\frac{1}{\sigma_{2}}}}
$$

Each labor bundle is a CES aggregate of workers of different skill types. The HS bundle contains degree holders of eight different types, corresponding to eight broad fields of study. The MS bundle contains vocationally trained workers, in the same eight broad fields of study. Finally, the LS bundle contains workers of four educational categories: primary and less, lower secondary, upper secondary, and pre-university. The choice of a three-bundle structure comes from an appreciation of the skill specificity at the different educational levels, ranging from relatively general skills at the lower end of the educational spectrum to relatively professionspecific skills at the higher end. The skill specificity is likely to be inversely related to the substitutability of workers at the given educational level:

$$
\begin{aligned}
& H S_{t}=A_{H S, t}\left[\sum_{f} \beta_{f} L D_{H S, f, t}^{1-\frac{1}{\sigma_{3}}}\right]^{\frac{1}{1-\frac{1}{\sigma_{3}}}} \\
& M S_{t}=A_{M S, t}\left[\sum_{g} \beta_{g} L D_{M S, g, t}^{1-\frac{1}{\sigma_{4}}}\right]^{\frac{1}{1-\frac{1}{\sigma_{4}}}} \\
& L S_{t}=A_{L S, t}\left[\sum_{l} \beta_{l} L D_{L S, l, t}^{1-\frac{1}{\sigma_{5}}}\right]^{\frac{1}{1-\frac{1}{\sigma_{5}}}}
\end{aligned}
$$

Each of the 20 skill types is composed of local and migrant labor:

$$
L D_{l f, t}=\left(\alpha_{l o c} L D L_{l f, t}^{1-\frac{1}{\sigma_{6}}}+\alpha_{m i g} M I G_{l f, t}^{1-\frac{1}{\sigma_{6}}}\right)^{\frac{1}{1-\frac{1}{\sigma_{6}}}}
$$

And local labor of skill type $s$ is made up of young and old workers:

$$
L D L_{l f, t}=\left(\alpha_{y} L D L A_{y, l f, t}^{1-\frac{1}{\sigma_{7}}}+\alpha_{n y} L D L A_{n y, l f, t}^{1-\frac{1}{\sigma_{7}}}\right)^{\frac{1}{1-\frac{1}{\sigma_{7}}}}
$$




\subsection{Labor Supply}

Each year, workers leave the labor force through death and retirement. ${ }^{8}$ New workers enter from the educational system, upon finishing an educational cycle and on deciding not to pursue further education. A skill-specific percentage of graduates (estimated from Labor Force Survey (LFS) data) do not enter the labor force.

\subsubsection{Educational Dynamics}

Facing the above demands for workers of various skill types, origin, and age, the evolution of supply of workers is determined in an educational module calibrated from data from past years. Students move between educational cycles depending on dropout rates, and the willingness to join the labor market at the end of each cycle. For low-skill content cycles, these rates are calculated as averages from the period 2009 to 2010 . The dropout rates are calculated using the following formula:

$$
\text { dropout }_{c}=\frac{\text { enrolled }_{c, 2009}+\text { entrants }_{c, 2010}-\text { grad }_{c, 2009}-\text { enrolled }_{c, 2010}}{\text { enrolled }_{2009}}
$$

For each cycle, the dropout rate is calculated as a residual. It corresponds to disappearances from the stock of enrolled between 2009 and 2010, which are not accounted for, relative to the stock of enrolled in 2009. We make the assumption that repetition rates (for which we have no information) are negligible. Graduates deciding not to pursue further education are captured by the parameter exdip:

$$
\operatorname{exdip}_{c}=\frac{\operatorname{grad}_{c, 2009}-\sum_{c}\left(\text { entrants }_{c, 2010} \times \text { transmap }_{c, c 2}\right) \times \frac{\operatorname{grad}_{c, 2009}}{\sum_{c}\left(\text { equiv }_{c, c 2} \times \operatorname{grad}_{c 2,2009)}\right.}}{\operatorname{grad}_{c, 2009}}
$$

where transmap is a mapping parameter between different educational cycles and equiv parameter mapping cycles that are equivalent, in the sense that they can both precede $c 2$. Thus, graduates who choose not to pursue into the next cycles are the residual of the graduates from cycle $c$, less entrants into the next cycle weighted by the importance of cycle $c$ as a cycle of origin. As such, exdip refers to the percentage of graduates who leave a given cycle in 2009, less those who choose to continue into any of the next possible cycles:

$$
\operatorname{NEWENR}_{c, t}=\text { popent }_{c, t}+\sum_{c} G R A D_{c 2, t-1} \times \operatorname{transmap}_{c, c 2} \times\left(1-\operatorname{exdip}_{c, t-1}\right)
$$

Newly enrolled are equal to children arriving at school age (popent) for the primary cycle, plus last year graduates from preceding cycles, less those who choose

\footnotetext{
${ }^{8}$ The mortality and retirement rates were obtained from UNESCO data.
} 
not to pursue further studies. Thus, the number of enrolled is simply equal to the number of enrolled of the previous year, less graduates and dropouts, plus newly enrolled in the current year:

$$
E N R_{c, t}=E N R_{c, t-1} \times\left(1-\text { dropout }_{c}\right)-G R A D_{c, t-1}+N E W E N R_{c, t}
$$

Furthermore, we assume a stable share of graduates:

$$
G R A D_{c, t=\text { gradrate }_{c} \times E N R_{c, t}}
$$

Students hence move through the educational system cycle by cycle, depending on dropout rates and the willingness to pursue further education, a willingness that is determined by preferences and the expected rate of return to education. At the end of Form 5, students who choose to pursue higher education make a choice of entering pre-university education or seeking vocational training.

\subsubsection{Educational Choices}

The hypothesis that expected wages orient the demand for a certain level of education has been confirmed in numerous studies (e.g., McIntosh (2001) and Canton and de Jong (2005)). Average wages by skill type and field of study have been found to be positively correlated with relative demand for education of a particular skill type and in a particular field of study (Montmarquette et al. 2002; Freeman and Hirsch 2008; Beffy et al. 2012). In Belgium, Duchesne and Nonneman (1998) find some support for relative wages, driving enrollment choices both in university and nonuniversity higher education. The choice between pre-university education and vocational training is thus modeled through a constant elasticity of transformation (CET) function where the first-order conditions render the following demands for vocational training and academic degrees, respectively ${ }^{9}$ :

$$
N E W E N R_{v o c, t}=\alpha_{v o c} \times \operatorname{TOTNEWENR}_{t} \times\left[\frac{\frac{\sum_{g}\left(L D_{g, t} \times\left(1-U r_{g, t}\right) \times a v f w_{g, t}\right)}{\sum_{g}\left(L D_{g, t}\right)}}{\frac{\sum_{f}\left(L D_{f, t} \times\left(1-U r_{f, t}\right) \times a v f w_{f, t}\right)}{\sum_{f}\left(L D_{f, t}\right)}}\right]^{\sigma_{10}}
$$

\footnotetext{
${ }^{9}$ See the Annex for the initial CET functions. The logic behind the use of a CET function to model educational demands is analogous to that of an income-maximizing firm choosing between exports and the domestic market as an outlet for its production. The representative agent maximizes expected income, subject to the constraint that total endowment in higher education is defined using a constant elasticity of transformation function. This maximization thus gives the optimal allocation of the educational endowment between vocational and general higher education.
} 


$$
\begin{aligned}
N E W E N R_{\mathrm{deg}, t} & =\alpha_{\mathrm{deg}} \times \text { TOTNEWENR }_{t} \\
& \times\left[\frac{\frac{\sum_{f}\left(L D_{f, t} \times\left(1-U r_{f, t}\right) \times a v f w_{f, t}\right)}{\sum_{g}\left(L D_{f, t}\right)}}{\frac{\sum_{g}\left(L D_{g, t} \times\left(1-U r_{g, t}\right) \times a v f w_{g, t}\right)}{\sum_{g}\left(L D_{g, t}\right)}}\right]
\end{aligned}
$$

The demand for vocational training thus increases according to the expected relative mean wage of vocationally trained and degree holders, respectively, and with an elasticity of $\sigma_{10}$. The total number of students having decided to pursue education after finishing secondary school is thus broken down into two categories: students who continue to vocational training and students who go on to university. For medium and high skilled, newly enrolled choose different fields of study based on preferences and expected wages in each field. This choice is again modeled through a constant elasticity of transformation (CET) function, which gives an optimal allocation of demand for skills given expected wages. We here assume that workers have myopic expectations and believe the wage distribution by skill to remain constant and equal to that of the previous year. The first-order conditions imply the following demand for educational services of type $f$, for vocational and university students, respectively:

$$
\begin{aligned}
& \operatorname{NEWENRFIELD~}_{g, t}=\gamma_{g} \times N E W E N R_{v o c, t} \times\left[\frac{a v f w_{g, t-1}\left(1-U r_{g, t-1}\right)}{a v f w t o t_{v o c, t-1}}\right]^{\sigma_{11}} \\
& \operatorname{NEWENRFIELD~}_{f, t}=\gamma_{f} \times N E \text { WENR }_{\mathrm{deg}, t} \times\left[\frac{a v f w_{f, t-1}\left(1-U r_{f, t-1}\right)}{a v f w t o t_{\mathrm{deg}, t-1}}\right]^{\sigma_{12}}
\end{aligned}
$$

where avfwtot edu,t-1 $_{\text {is }}$ ise average expected wage of diploma- and degree-holding non-youth on the labor market, with voc,deg $\subset e d u$. Each year, NEWENR edu,t $_{\text {is }}$ fixed and equal to the demand for vocational and university studies, respectively. These blocks of equations thereby give us educational demand by skill. These demands are confronted with supply in a sequential fashion: first, fields of study are ranked according to the wage premium associated with each one. Then, desired entrants into that field are confronted with the number of available places in the field. Students not accepted are regrouped with those desiring to enter the second rank field. A second cutoff is carried out, with leftovers going into the third ranked field of study. The mechanism is repeated throughout the list of fields of study, for vocationally trained and degree holders, respectively. Any students cut off from the eighth field of study are considered to be secondary school graduates of which a fraction will enter the labor force. 


\subsubsection{Labor Force Evolution}

Graduates from lower cycles are added to the youth labor force in the following fashion:

$$
\begin{aligned}
& \operatorname{LSTA}_{l f, y, t}=\text { LSTA }_{l f, y, t-1} \times\left(1-\text { transage }_{l f}\right) \\
& +\sum_{c}\left(\operatorname{GRAD}_{c, t-1} \times \operatorname{exdip}_{c} \times \text { edumap }_{c, l f} \times\left(1-\text { inact }_{l f}\right)\right) \\
& \left.+\sum_{c 2}\left(\text { ENR }_{c, t} \times \text { dropout }_{c} \times\left(1-\text { inact }_{l f}\right)\right) \times \sum_{c}\left(\text { transmap }_{c, c 2} \times \text { edumap }_{c, l f}\right)\right)
\end{aligned}
$$

That is, the local labor force of skill $l f$ equals the previous year's local labor force of skill $l f$, less those workers who flow from the young to the not young category. Graduates from cycle $\mathrm{c}$ who choose not to continue their studies are mapped to a labor skill, and a percentage of them are added to the labor force according to their labor force participation rate. Finally, dropouts from cycles above $c$ are added to the relevant labor force category using mapping parameter transmap, denoting passages between cycles. For vocational and university students, the logic is the following:

$$
\begin{aligned}
& \operatorname{LSTA}_{l f, y, t}=\operatorname{LSTA}_{l f, y, t-1} \times\left(1-\text { transage }_{l f}\right) \\
& +\min \left(\text { CANDID }_{l f, t-n}, \text { places }_{l f, t-n}\right) \times \text { inact }_{l f}
\end{aligned}
$$

The labor force holding diplomas and degrees is thus equal to diploma and degree graduates in the labor force the previous year, less those who transit to the not young category. Students who were accepted into their desired field of study are added, a percentage being removed depending on the labor participation rate of the category in question. The index $\mathrm{n}$ reflects the time it takes to complete a given cycle. We have set $\mathrm{n}$ to equal 4 years for all degree students, and 2 years for all vocational degrees, reflecting the average duration of these cycles in Malaysia. The inclusion of a delay between entrance in a given field and labor market participation has important implications. During the time of studies, workers are effectively immobilized, such that any increase in the number of students is likely to carry an initial negative impact on growth. In short, instead of being potential low-skilled workers, these individuals do not contribute directly to production. We thus include a temporal dimension of the efficiency of education policy in the model.

Finally, the evolution of older workers depends on the transit rate between age groups and the mortality and retirement rates of old workers:

$$
\begin{aligned}
\operatorname{LSTA}_{l f, n y, t} & =\operatorname{LSTA}_{l f, n y, t-1} x\left(1-\text { mort }_{l f, t}-\text { retir }_{l f, t}\right) \\
& + \text { transage }_{l f} \times \operatorname{LSTA}_{l f, y, t-1}
\end{aligned}
$$




\subsection{The Migrant Block}

Immigration in Malaysia has increased substantially over the last decades, potentially influencing labor market dynamics. These migrants tend to be low educated, arriving in Malaysia from primarily Indonesia and the Philippines. Various push and pull factors explain the supply of migrants in Malaysia. We model the total supply of migrants using a CET function, where the evolution of the migrant stock at a given skill level depends on the relative wage premium of migration in a given year compared to the relative wage premium in the base year:

$$
S M I G_{l f, t}=\sum_{A C} I M M I G_{A C, l f, 2005} \times\left(\frac{\frac{\operatorname{avfwm}_{l f, t}}{w \text { dom }_{l f, t}}}{\frac{\text { avfwm }_{l f, 2005}}{w d o m_{l f, 2005}}}\right)^{\sigma_{8}}
$$

Furthermore, migrants move between sectors according to relative wages and initial preferences:

$$
S M I G_{l f, t}=\sum_{A C}\left[\gamma_{A C, l f} \times I M M I G_{A C, l f, t}^{1+\frac{1}{\sigma_{9}}}\right]^{\frac{1}{1+\frac{1}{\sigma_{9}}}}
$$

Migrants thus make their decision sequentially. First, the decision to migrate is taken based on expected wages and the elasticity of substitution. Once immigrated, they will reallocate between sectors depending on the wage rate and the elasticity of the migrant sectoral supply.

\subsection{Labor Market Adjustments}

Migrants and local workers' wages are assumed to be different due to an imperfect substitution by employers (Ozden and Wagner 2014). It is assumed that the local wage does not clear the labor market, such that there is unemployment among locals. The wage is modeled using a wage curve, reflecting the often observed empirical relationship between wage and unemployment. The local average wage by skill is thus given by

$$
\operatorname{logafw_{lf,t}}=\beta_{1, l f}+\beta_{2, l f} x \log U r_{l f, t}
$$

Sectoral wages are then equal to the average wage, plus an exogenous wage differential: 


$$
w f_{A C, l f, t}=a f w_{l f, t} \times f w d i s t_{A C, l f}
$$

Initially, the migrant wage clears the migrant labor market. We thus make the assumption that there is no migrant unemployment. Furthermore, reasonably in line with the regulatory framework, we assume that migrants do not pay social security. Following the minimum wage law passed in Malaysia in 2012, restrictions are imposed on the market wage from 2013. It follows that wages no longer clear the migrant labor market. Since there is no migrant unemployment, the introduction of a minimum wage - supposing it is binding - implies rationing of migrants in Malaysia. The level of the minimum wage is set according to the actual minimum wage introduced, deflated to reflect 2005 prices (since the model is exempt from inflation). The minimum wage is introduced sequentially. First, market wages below the minimum wage level are fixed at the minimum wage rate. The model is then resolved to allow for sectoral adjustments to take place. Any market wage having fallen below the minimum wage rate is fixed at the minimum wage, and the procedure is repeated. The sequence stops when all wages are equal to or above the minimum wage rate.

\subsection{Closure and Dynamics}

The model has five closures: a macro closure, a government closure, an external balance closure, a labor market closure, and a closure of the social security accounts. Concerning the macro closure, it is savings driven (households' marginal propensity to save is exogenous), which means that the level of investment is determined by the level of total available savings in the economy (including foreign savings). Hence as savings increase, the stock of capital and output increase. The government closure chosen consists in fixing government expenditures as a constant share of GDP and tax rates and leaving the government budget balance endogenous. The social security account is modeled separate from the government budget. It earns its income from employers' payroll taxes and pays benefits that are distributed to households. The social security balance is endogenous. The foreign balance closure consists of fixing the exchange rate and leaving the current account balance endogenous. The formal labor market closure consists of a joint determination of unemployment and average local wages through the wage curve described above and no unemployment for foreign workers (wages clear the market).

Model dynamics are of the sequential type. Capital accumulation is sectoral. Each year the stock of capital in each sector corresponds to last year's stock plus new investment, minus the depreciation of capital. Sectoral investment has been modeled as a function of the sectoral stocks of capital, sectoral rates of return to capital, and capital acquisition costs. As already mentioned, the evolution of the active population by skill is modeled within the education block, which relies on the actual performance rates of the educational system and endogenous educational 
choices in Malaysia. Government and foreign debts increase (decrease) with the yearly level of the net deficit (surplus) of government and foreign savings.

\section{Data and Calibration}

\subsection{The Database}

We build a social accounting matrix using an input-output table of 2005, the base year for the simulations. A social security contribution account has been added, with a fixed percentage of employer and worker contributions being drawn from labor income. Total employment is taken from the 2007 LFS, the first survey for which wages are available. It represents wage earners in each sector, with the exception of the agricultural sector where employment refers to all employed due to the particular nature of this sector (hosting many informally employed workers) ${ }^{10}$ and health (where employment corresponds to the estimated amount of wage earners for 2005).

Total value added (including social security benefits) in each sector is taken from the 2005 input-output (IO) table. Wage-related data come from the LFS. In the agriculture, health, and education sectors, aggregate wage bills are those of the 2005 IO tables. In the remaining sectors, wage bills are taken from the LFS 2007 by multiplying mean wages by skill and industry with the number of workers of that skill and industry (the difference between these and the original wage bill is imputed from capital remuneration). Thus, mean wages and wage earners are kept in accordance with the LFS in all except the three sectors mentioned. For those three sectors, the standard methodology could not be used since the imputed wage bill would necessitate a negative capital remuneration. The original wage bill is thus kept, and wages are imputed and not equal to those of the LFS.

Investment by origin is taken from the 2005 IO table and is portioned out to destination sectors. Information from a report titled "National Accounts Capital Stock Statistics" by the Department of Statistics proved very useful for this exercise. Since the data reflect a higher aggregation than the one used for the estimation, we assume that investment is equally distributed among our subsectors. Ideally, an investment origin-destination matrix would have been used, but such a matrix was not available. Current results will thus fail to accurately capture some subsector dynamics that are due to relatively high or low investment with respect to sector size. World and local growth rates are taken from the World Bank Databank. Data on enrollment, intake, and graduates for each cycle were available for 2009 and 2010. These data are used to calculate (for each cycle) the dropout rates and the share of graduates who move to the next cycle. Enrollment data for the base year are estimated from a dynamic calibration exercise, retracing the evolution of educational outcomes between 2005 and 2010.

\footnotetext{
${ }^{10}$ The LFS does not include workers in communal housing, which is common among migrant agricultural workers, who are thus likely to be underrepresented.
} 
Using production and LFS data from 2005 through 2011, we dynamically calibrate the main parameters of the model through an iterative process. The result from this exercise is that the reference scenario is reasonably in line with the survey figures and the evolution of the main variables at the macro and sectoral levels.

\subsection{Calibration}

Model parameters include initial values of endogenous variables, as well as exogenous parameters. The social accounting matrix provides such values for production and consumption, exports, imports, etc. Labor Force Surveys provide us with information on wages and employment status of migrants and locals. Some unobservable parameters can be calculated using initial values obtained from these sources. Others, such as elasticities of substitution, have to be estimated. When possible, we have attempted to estimate these elasticities. When impossible, reasonable values from the literature have been used.

As for the demand elasticity of substitution between high-skilled labor and capital, we follow Card and Lemieux (2001) and derive elasticities of substitution between workers of different age groups, education levels, fields of study as well as elasticities of different labor aggregates of these worker categories. The limited number of years for which we have data on wages sharply limits the regression results, and significant coefficients were not obtained for the full production structure. There are, however, indications of elasticities decreasing as we move up the production structure. The price elasticities of demand for migrants with respect to locals have been estimated from LFS data. ${ }^{11}$

We consider current macroeconomic trends to prevail. As such, the savings rate and the rate of increase of foreign direct investment have been set to values producing reasonable figures, in line with IMF data for the period 2005-2011. Furthermore, we are assuming the government deficit to continue its downward trend, declining to $3 \%$ of GDP in 2015 and completely absorbed in $2020 .{ }^{12}$

\section{A Microsimulation Module}

A microsimulation module is added to the CGE framework in order to study distributional impacts of SBTC and educational rationing. Since we are focusing on wage inequalities, a microaccounting approach is used, linking model outcomes to microlevel data. The LFS survey contains information on wage earners only, which is why we exclude interest rate variations from our analysis.

\footnotetext{
${ }^{11}$ We thank Caglar Ozden and Mathis Wagner for providing us with these elasticities.

${ }^{12}$ As by PEMANDU objectives.
} 
We use the most recent exhaustive LFS dataset, that of 2010, to implement factor price variations. Since our simulations produce effects that are likely to be important only in the medium- to long-term framework (especially considering educational rationing), we seek to examine the alternative effects by 2020 from our reference scenario and our simulated scenarios. In a sense, we are comparing two counterfactuals. The variation in real wage income between 2010 and 2020 for an individual in industry $A C$, of skill $f$ and age group $a$, is thus

$$
\Delta W_{2020 / 2010, A C, f, a}=W_{2010, A C, f, a} \times C_{s c e n, A C, f, a}
$$

where $\mathrm{C}$ is a vector of factor payment variations issued from the various macro model scenarios. Thus, the individual wage impact of a simulation simply amounts to:

$$
\Delta W_{A C, f, a}=W_{2010, A C, f, a} \times\left(C_{s i m, A C, f, a}-C_{r e f, A C, f, a}\right)
$$

Since our interest in doing this exercise is to examine how skill-biased technological change and educational policy affect distribution of wage incomes, we look at Gini coefficients and decile ratios, included along with macro results in the following section.

\section{Simulations and Results}

The following section presents the simulations run and their results. Our first simulation assumes the skill bias of technological change to be zero, i.e., that the overall rate of technological progress, calibrated from the dynamic calibration exercise using exogenous productivity growth rates, is affecting skilled and unskilled labor alike. Secondly, we simulate a rationing in the number of places at institutes of higher learning. For simplicity's sake, we compare an open-door policy, considered to be our benchmark scenario, with a scenario where the number of places available is equal to that of 2005 , our base year.

In terms of lowering enrollment figures, other educational policies could have been considered, such as increasing fees, which would have an enrollment-reducing effect. The effects in terms of rationing would be similar, although the household share of the cost borne would have increased. ${ }^{13}$ Attempting to increase quality rather than quantity is another potential policy candidate. Modeling increases in the quality of education (as measured by the skill endowment of graduates and not the internal efficiency of the educational system) are, however, not straightforward.

\footnotetext{
${ }^{13}$ Since our intent is to study the SBTC, educational policy nexus, and its links to wage inequality, and not to compare different sources of financing of the educational system and their effects on inequality, we contend that the rationing of places is a more straightforward policy to examine.
} 


\subsection{Malaysia Without Skill-Biased Technological Change}

What would have been the absorption of graduates by the labor market if technological progress in Malaysia were not biased toward skilled labor? How would the wage premia have reacted? We run a twofold reference scenario, one with and one without skill-biased technological progress, both calibrating overall productivity growth given exogenous sectoral productivity growths and GDP growth rates (using historical figures, then assumed to be 5\%). The reference scenario has been calibrated in order to reproduce as closely as possible the evolution of wages, unemployment, and other endogenous variables between 2005 and 2011. We have settled on a skill bias of $4 \%$ annually for two reasons. Firstly, an estimation of the residual $\mathrm{A}=\Delta \frac{\theta_{S}}{\theta_{U}}$ from only four data points (the ones for which we have wages) gives us an upper limit of skill-biased technological change of $9 \%$. Choosing roughly half this figure makes us reasonably sure we are not overestimating the effect of SBTC. Furthermore, this figure gives us a reference scenario reasonably in line with the evolution of some main macro and sectoral variables.

Our first simulation assumes neutral technological change. Since the global productivity coefficient is calibrated to sectoral productivity growth rates and a GDP target figure, this means that removing the skill bias does not imply modifying aggregate productivity growth. Furthermore, the skill-biased technological change was applied to all tertiary educated, i.e., certificate, diploma, and degree holders. As can be seen from Fig. 9.3, in the absence of skill-biased technological change, less-

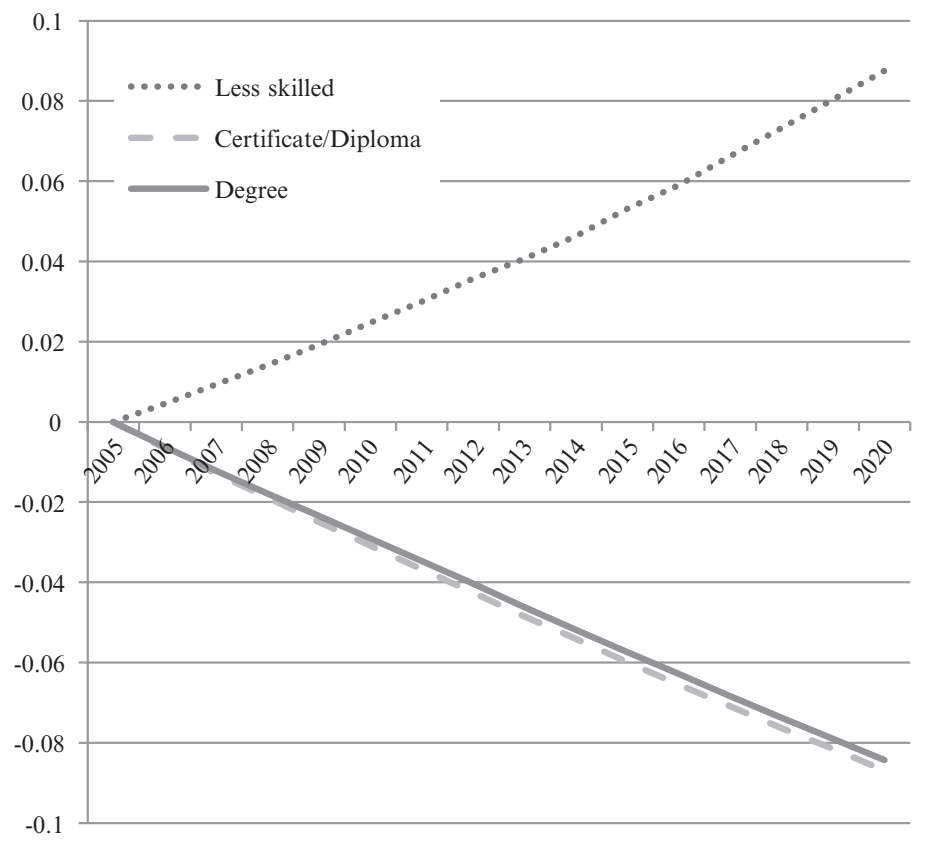

Fig. 9.3 Evolution of wages of Malaysian wage earners without SBTC. (Source: Authors' calculations using results from the model) 


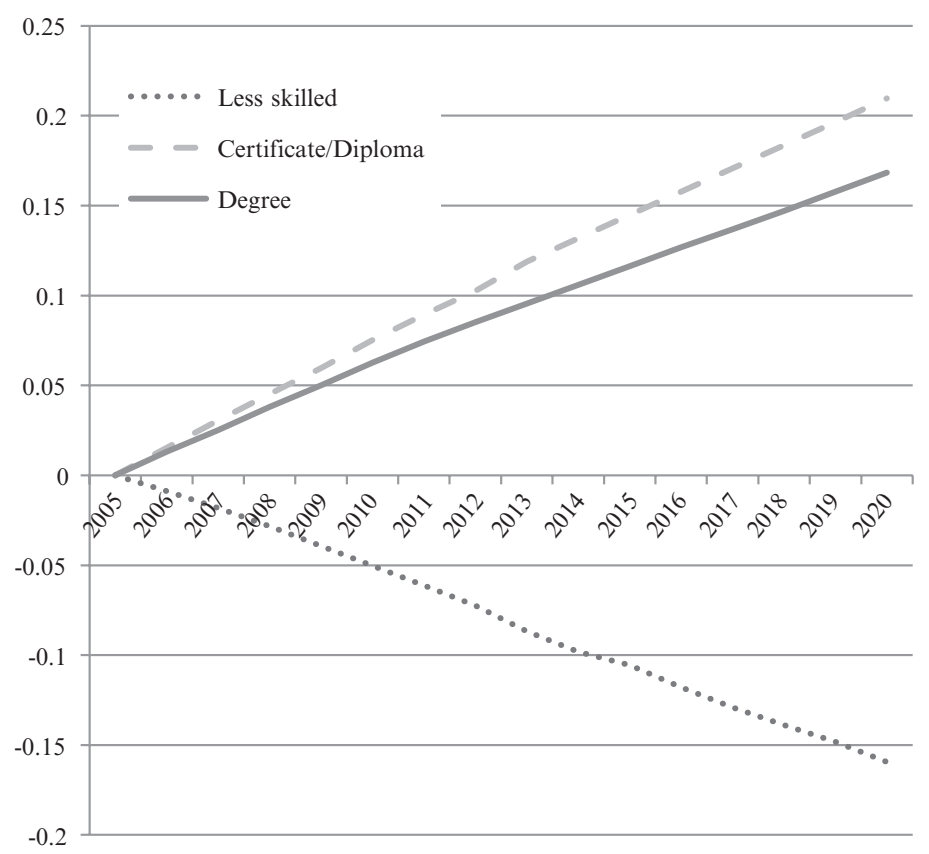

Fig. 9.4 Evolution of unemployment of Malaysian wage earners without SBTC. (Source: Authors' calculations using results from the model)

skilled workers would have had a higher wage growth than in the reference scenario. On the other hand, tertiary educated - vocationally and academic alike - would have seen their wages decrease, thus eroding returns to education. Detailed breakdowns by field of study for diploma holders and degree holders and by level of education for less skilled can be found in the Annex. They show that for diploma holders, the biggest winners from SBTC are engineers. For degree holders, those with degrees in agriculture have benefited the most. Figure 9.3 shows that the agricultural sector has known the highest upskilling in the period 2007-2010. This large sector has the highest ratio (more than 95\%) of unskilled to skilled labor, implying that an important substitution of skilled for unskilled labor needs to take place, significantly affecting wages of the high skilled.

Looking at unemployment (Fig. 9.4), we see that the tendency is the same as for wages. Had skill-biased technological change not been present, the unemployment rates of tertiary educated would have been around 15-20\% higher, while those of less-skilled workers would have been $15 \%$ lower. Thus, SBTC has clearly had a positive impact on the labor market outcomes of graduates in Malaysia.

The macroeconomic impacts over the period are minor (mainly since the model is calibrated to the same GDP target figures). Unemployment would however have been slightly lower during the period but returning to a very close figure (3.1\%) by 2020. Results also show that immigration would have been higher had SBTC not prevailed, since this would have stimulated growth of migrant-intensive sectors 
Table 9.4 Sectoral production growth differentials 2010-2020 without SBTC (private sectors)

\begin{tabular}{l|r}
\hline Agriculture & $11 \%$ \\
\hline Oil and gas & $3 \%$ \\
\hline $\begin{array}{l}\text { Manufacturing food, beverages, } \\
\text { tobacco }\end{array}$ & $10 \%$ \\
\hline Manufacturing textile & $2 \%$ \\
\hline Manufacturing wood & $12 \%$ \\
\hline Manufacturing paper and furniture & $3 \%$ \\
\hline Manufacturing chemicals rubber & $-1 \%$ \\
\hline Metals, machinery, equipment NEC & $0 \%$ \\
\hline Electronics and electrical & $-2 \%$ \\
\hline Manufacturing and transport & $-1 \%$ \\
equipment & \\
\hline Utilities & $1 \%$ \\
\hline Construction & $1 \%$ \\
\hline Wholesale and retail & $8 \%$ \\
\hline Accommodation and restaurants & $5 \%$ \\
\hline Logistics & $4 \%$ \\
\hline Post and telecom & $0 \%$ \\
\hline Finance & $-1 \%$ \\
\hline Real estate & $0 \%$ \\
\hline Business services & $-10 \%$ \\
\hline
\end{tabular}

Source: Authors' calculations using results from the model.

more than in a scenario with SBTC. Malaysia's immigration in recent years has been important, important enough to spark a concern among the government about its economic and social impact. Unbiased technological progress, relatively more favorable to low-skill-intensive sectors, can thus be seen as increasing the pull factor in the Malaysian context, where the main migration pool is made up of low-skilled Indonesians and Filipinos. ${ }^{14}$ Had productivity increases been unbiased, the migrant stock would have been $14 \%$ higher by 2020 .

Table 9.4 shows the production growth differentials from 2010 to 2020 in the absence of skill-biased technological change. It suggests that SBTC has led to structural change, benefiting sectors such as business services, finance, and certain types of manufacturing, the common denominator of which is a large share of skilled labor. Symmetrically, it has played a role in the relative decline of sectors such as wood or wholesale and retail. Thus, the recent evolution of Malaysia toward a more skill-intensive economy, a policy target, has been facilitated by technical progress biased toward skilled labor.

\footnotetext{
${ }^{14}$ According to the 2010 Labor Force Survey, the proportion of employed migrants with at least a diploma or certificate in 2010 stood at less than $4.5 \%$. The equivalent figure for Malaysians is $22 \%$. The bulk of Malaysia's immigrants being low-skilled immigrants, migration responds strongly to variations in low-skilled wages, which are related to the skill bias of technological progress.
} 


\subsection{Constraining the Supply of Higher Education}

Our reference scenario supposes no rationing of supply of educational services in Malaysia. Demand factors alone thus determine the evolution of skilled labor. In this simulation, we restrain the supply of educational services to that of the base year, 2005. Every year, the number of places in each field of study is thus equal to the number of places available in $2005 .{ }^{15}$ We here assume the cycle of diploma studies to be 2 years and that of degree studies to be 4 years. An increased enrollment in degree studies would therefore only create an increase in high-skilled labor 4 years later.

Figure 9.5 shows the evolution of unemployment of various high-skilled categories when places are kept constant. Unsurprisingly, by 2009, as the effects translate into a lower amount of degree holders than in the reference scenario, the unemployment of degree holders starts to decrease. At the end of the period, unemployment rates are $35 \%$ to $50 \%$ lower than in the reference scenario. The effect is also felt on wages, which would have been up to $20 \%$ higher by the end of the period (see Annex). By constraining access to higher education, a rent is created and awarded to those in possession of a tertiary education. For diploma holders, there is more variation in unemployment decreases and wage increases (See Annex). Some fields of study experience large increases while others get relatively minor ones. In particular, diploma holders in health do not benefit much from the rationing. This is partially due to the fact that the demand for health diplomas was falling in the reference scenario. Rationing actually creates a slight increase in the long-term supply of health diploma graduates, since some of those diploma students that are cut out from more desirable fields due to rationing end up joining health programs as a fallback option (Table 9.5).

Looking at sectoral production growth differentials over the decade 2010-2020, we find disparate results across sectors. Several mechanisms are at play. Firstly and most intuitively, rationing increases the relative cost of skilled labor. Sectors that are relatively intensive in unskilled labor will thus benefit. The most unskilled laborintensive sectors (agriculture, wood, wholesale and retail trade) are therefore those where production increases the most. Symmetrically, the most skill-intensive sectors (business services, finance, and manufacturing of transport equipment) see their production decrease. Secondly, a variation of wage costs affects most those sectors that are relatively labor intensive. This explains why manufacturing of wood benefits more than agriculture from the rationing, agriculture being more capital intensive. Among the relatively skill-intensive sectors, the most capital-intensive sectors such as finance are less hurt by the rationing than relatively labor-intensive ones such as business services.

Looking at Figs. 9.15-9.17 in Annex 1 provides insight into the determinants of wage shifts and their sensitivity to variations in these determinants. Skill-biased

\footnotetext{
${ }^{15} \mathrm{An}$ important caveat here is that we do not actually know the number of places in 2005 , only the number of enrolled in each field of study. It is possible that more places were available in some fields.
} 


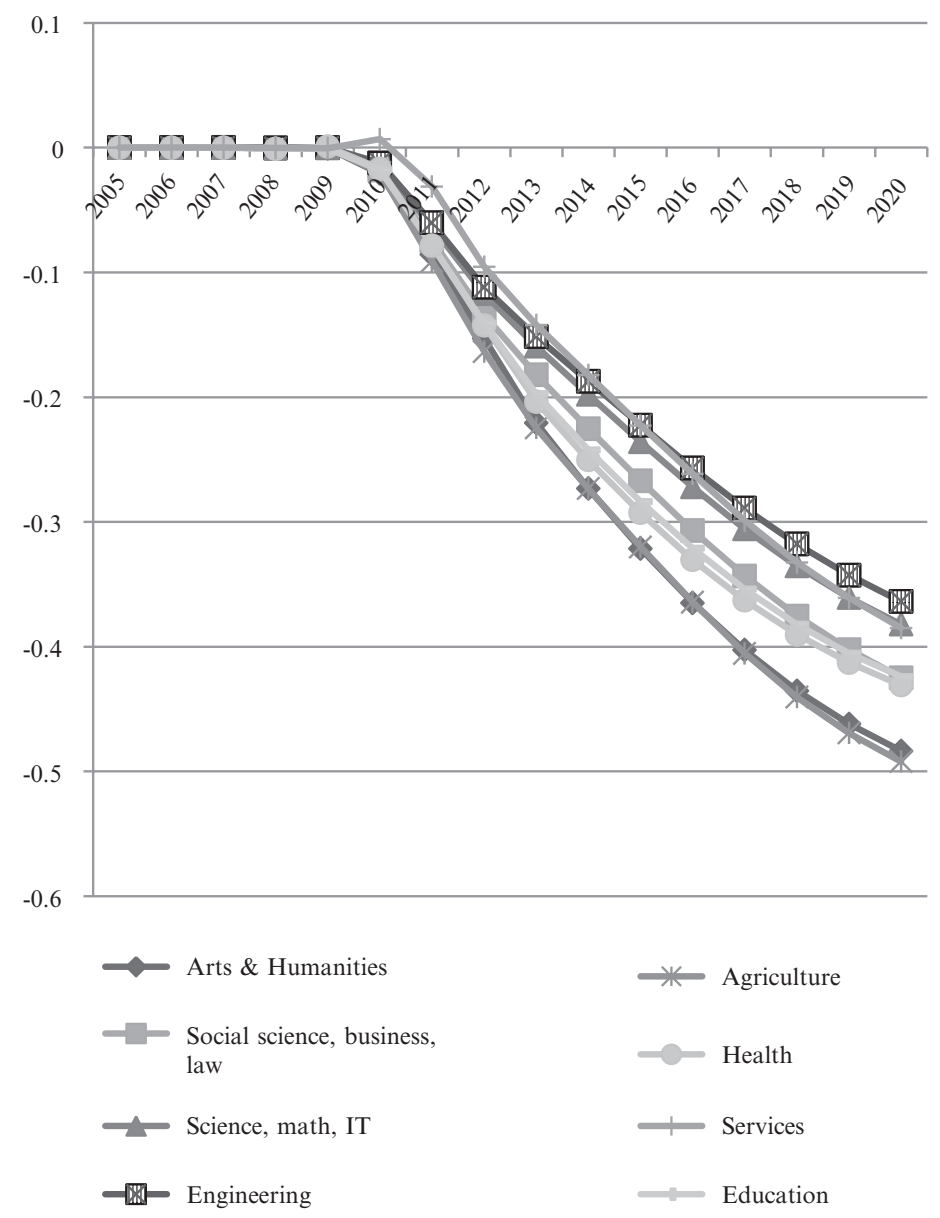

Fig. 9.5 Evolution of unemployment of degree-holding wage earners with a restriction in places. (Source: Authors' calculations using results from the model)

technological change is indeed a strong one, as has been shown in the previous results. However, the magnitude of the bias sharply correlates to the subsequent wage loss (gain) of more (less) skilled workers. Furthermore, the elasticity of substitution between the three main labor bundles is also a strong determinant of the distributional effects of skill-biased technological change and educational rationing. We feel that our main hypotheses are reasonable. Our main variable, the skill shifter, is at $4 \%$, although the residual estimated stood at $9 \%$. The elasticity of substitution between skilled labor bundles is also conservatively set at 1.5. As a matter of comparison, Katz and Murphy (1992) find an elasticity of supply between high school and college labor of 1.4 for the United States. They do not, however, implicitly account for substitutability within these two labor aggregates. When doing so, Card and Lemieux (2001) find estimates ranging between 2 and 2.5 in the UK and United States. 
Table 9.5 Sectoral production growth differentials 2010-2020 with rationing (private sectors)

\begin{tabular}{l|r}
\hline Agriculture & $3.6 \%$ \\
\hline Oil and gas & $1.4 \%$ \\
\hline $\begin{array}{l}\text { Manufacturing food, beverages, } \\
\text { tobacco }\end{array}$ & $3.0 \%$ \\
\hline Manufacturing textile & $1.1 \%$ \\
\hline Manufacturing wood & $4.5 \%$ \\
\hline Manufacturing paper and furniture & $1.4 \%$ \\
\hline Manufacturing chemicals rubber & $-0.1 \%$ \\
\hline Metals, machinery, equipment NEC & $0.1 \%$ \\
\hline Electronics and electrical & $0.1 \%$ \\
\hline Manufacturing and transport & $-0.5 \%$ \\
equipment & \\
\hline Utilities & $0.5 \%$ \\
\hline Construction & $0.4 \%$ \\
\hline Wholesale and retail & $4.8 \%$ \\
\hline Accommodation and restaurants & $2.2 \%$ \\
\hline Logistics & $1.9 \%$ \\
\hline Post and telecom & $0.2 \%$ \\
\hline Finance & $-0.4 \%$ \\
\hline Real estate & $0.1 \%$ \\
\hline Business services & $-5.1 \%$ \\
\hline Source Auts
\end{tabular}

Source: Authors' calculations using results from the model.

\subsection{Distributional Results}

The microaccounting exercise shows that the scenarios considered have substantially different impacts on Gini coefficients and interdecile ratios. In all cases, however, the massification of higher education together with SBTC brings about a decrease in overall wage inequality, as confirmed by the systematically lower Gini coefficients of our counterfactual scenarios. The same holds true for the interdecile measures, which are systematically lower than in the 2010 LFS (the exception being the p90/p50 indicator in Simulation 2) and the Atkinson index. The Atkinson index emphasizes inequality at the lower end of the distribution to affect the index more than inequality at the upper end and the more so the higher the inequality aversion parameter $e .^{16}$

As stated above, the reference scenario corresponds to skill-biased technological change and an open-door educational policy. This is what we consider to be the path Malaysia is currently on. The increased educational attainment of Malaysians will

\footnotetext{
${ }^{16}$ As long as $e$ greaterthan 0 , the sensitivity to inequality in the lower end of the distribution is increasing in $\mathrm{e}$. We have chosen to set $e=1$ in the simulation.
} 
lead to a wage compression, substantially reducing wage inequality (almost a 3-point drop in the Gini coefficient). When comparing this with a situation without SBTC, maintaining the educational policy, the corresponding drop in the Gini is about 4.1. Skill-biased technological change thus prevented a reduction in wage inequality over the period. Similarly, both interdecile ratios would have been lower, had SBTC not been present (Table 9.6).

Turning to educational policy, the second simulation shows the counterfactual Gini coefficient and interdecile ratios in a situation with SBTC and with educational rationing. Thus, the Gini coefficient would have been 1.6 points higher had the number of educational places been maintained at their 2005 level. The open-door policy of the Malaysian government has thus contributed to a decrease in wage inequality. It should be noted that even in this scenario, the counterfactual Gini coefficient for 2020 is lower than the one computed from the 2010 LFS data. This is because demographic factors, namely, the fact that the low-skilled working population is older than the high-skilled one, contribute to an increase in the share of skilled labor even when higher education is rationed. Also, the introduction of the minimum wage in 2013 contributes to an inequality-reducing compression of the wage distribution. The different simulations are thus to be understood as deviations from this general downward-sloping trend. Turning to Simulation 3 (no SBTC, rationing), it shows that the impact of rationing is lower, but not far from that of SBTC. It thus seems that the open-door educational policy has counteracted the inequality maintaining effect of skill-biased technological change in Malaysia.

The full story of educational impacts on inequality should mention social returns to education. While private returns have largely been the focus of the literature (although a sizeable literature on social returns to education exists), externalities of educational accumulation might impact the distribution of income in indirect ways. Primarily, there is an evident link between education and the innovation process, likely to impact technical progress directly. The impact of this nexus on the relative productivity bias is however uncertain, and we therefore assume the absence of such an effect. Secondly, spillover effects in worker productivity might be expected. It is plausible that an individual in training will increase not only his or her productivity but also that of his or her coworkers, for example, by introducing new ideas or forms of organization of the

Table 9.6 Summary of distributional indices from microaccounting exercise

\begin{tabular}{l|l|l|l|l|l}
\hline & & Ref. & Sim. 1 & Sim. 2 & Sim. 3 \\
\cline { 2 - 6 } & $\begin{array}{l}2010 \\
\text { LFS }\end{array}$ & $\begin{array}{l}\text { SBTC, no } \\
\text { rationing }\end{array}$ & $\begin{array}{l}\text { No SBTC, no } \\
\text { rationing }\end{array}$ & $\begin{array}{l}\text { SBTC, } \\
\text { rationing }\end{array}$ & $\begin{array}{l}\text { No SBTC, } \\
\text { rationing }\end{array}$ \\
\hline Gini coefficient & 0.40743 & 0.3782 & 0.36686 & 0.39393 & 0.38078 \\
\hline $\begin{array}{l}\text { Atkinson index } \\
(1)\end{array}$ & 0.24532 & 0.2143 & 0.20306 & 0.23019 & 0.21683 \\
\hline p90/p10 & 6.415 & 5.66 & 5.458 & 6.133 & 5.695 \\
\hline p90/p50 & 2.52 & 2.399 & 2.301 & 2.559 & 2.425 \\
\hline
\end{tabular}

Source: Authors' calculations using results from the model. 
workplace. This is perhaps the most relevant type of externality for our purposes. Acemoglu and Angrist (1999) try to estimate social returns using variations in compulsory schooling laws in US states. They find little evidence of a higher social than a private return. Furthermore, to our knowledge, there are no studies trying to estimate the social returns to education in Malaysia. Again, we are unable to ascertain any impact on the skill bias of technological change from these mechanisms.

\subsection{The Hypothesis of Exogenous SBTC}

A major drawback of the canonical model of skill-biased technological change (Acemoglu and Autor 2011) is that it says nothing about the origin of SBTC. Could it not be that the increase of skilled labor has provoked the direction taken by technical bias? Acemoglu $(1998,2002)$ creates a model in which a marketplace for innovation exists, and firms can choose to develop technologies suited to one factor of production rather than the other. He shows that whatever the elasticity of substitution between factors, an increase in the relative abundance of one creates some amount of technical change biased toward that factor. This however relies on profit incentives as the main source of the direction of technological bias. While arguing that innovation might indeed not be driven by profits, the direction of innovation somehow is. No clear explanation is given as to why this would be the case.

If SBTC results from firm responses to modifications of factor proportions, then this type of mechanism should be the most prevalent in countries that carry out a lot of innovation domestically, such as high-income economies. To our knowledge, only one paper has tested for endogeneity of SBTC, in the German context (Bogliacino and Lucchese 2015). Using the influx of East Germans as a source of exogenous variation in the proportion of skilled labor, they conclude on the absence of a demand-pull effect on skill-biased technological change. The experience of MENA countries and their record-high unemployment rates for tertiary graduates can also be raised as an argument for the absence of a demand-pull effect. The considerable increases in quantities witnessed by these countries have not been followed by job creation suited to their qualifications.

In an era of openness and globalization, innovation travels fast. Berman et al. (1998), using data from 12 countries, show that skill-biased technological change such as the one observed in the United States has been pervasive, occurring simultaneously in all countries. Berman and Machin (2000) further show that this pervasiveness extends to middle-income countries (of which Malaysia is one) in the 1980s, whose skill upgrading is correlated with that of the United States. Since the world has 
not ceased to be a globalized place, it is likely that the same kind of pervasiveness of SBTC is at least as evident today as three decades ago. The hypothesis of SBTC through imports of goods which embody skill bias has been tested by Conte and Vivarelli (2011), who find evidence of such a mechanism on a set of 23 low- and middle-income countries in the period 1980-1991. Eaton and Kortum (2001) show that the production of capital goods is highly concentrated among seven OECD countries which provide the main source of imports of capital goods for the rest of the world.

Cross-country regressions and the little evidence testing directly the demandpull hypothesis thus suggest that SBTC is at least partly unrelated to the proportion of skilled labor in the economy. In the Malaysian case in particular, being a middle-income country relying on imports of capital goods to a larger extent than high-income countries (and in particular, high-technology countries such as Germany), there is reason to believe that much of the technological bias experienced is embodied in imported technology.

If SBTC is to a large extent exogenous with respect to skill proportions, the results of our simulations are valid. Should a significant share of SBTC be due to the increase in skilled labor, this would nuance some of the results obtained but would not change their rank order. Simulation 1 would slightly overestimate the drop in the skill premia and subsequently the reduction in the inequality measures. Simulation 2 would slightly underestimate the increase in skill premia and subsequently the reduction in the inequality measures.

\section{Conclusion}

This article has looked at the labor market impacts of two alternative scenarios: a neutral technological change and a rationing of places available in tertiary education. We develop a dynamic general equilibrium framework in which we extensively model educational choices both on the demand and the supply side, while taking into account immigration decisions. We are thus able to fully endogenize labor supply dynamics in the Malaysian context.

Our results show that in the absence of skill-biased technological change, relatively skilled wage earners should have expected lower wages and higher unemployment, while unskilled labor would have been able to expect higher wages and lower unemployment. The absence of SBTC would also have meant increased migration. We also show that skill-biased technological change has led to structural change, benefiting sectors with a large share of skilled labor, such as business ser- 
vices. Furthermore, our model does not take into account geography. A limitation of the study is thus that territorial inequalities or geographical shifts of production linked to internal migration of relatively more-/less-demanded skills across administrative divisions are ignored.

With rationing of the supply of higher education, we find that rents are created for high-skilled workers, who would have seen their wages increase and unemployment decrease. At the sectoral level, we identify two mechanisms affecting sectoral production growth: relatively less-expensive unskilled labor, benefiting low skillintensive sectors, and substitution effects among high skill-intensive sectors favoring the more capital-intensive sectors. These macro effects translate into distributional effects in the microaccounting module. We show that skill-biased technological change and rationing of educational services both have adverse effects on wage inequalities in the medium term (their presence generates a Gini index of 0.394 in 2020 compared to 0.367 in their absence), although even with both mechanisms in play we would expect wage inequalities to drop. It seems therefore that the expansive educational policy adopted in Malaysia has counteracted some of the increase in inequalities expected from skill-biased technological change. The presence of skill-biased technological change in Malaysia thus constitutes a case for continued open enrollment policies to reduce wage inequalities.

In this paper we assume that total factor productivity and skill bias are unrelated, to be able to isolate the effect of skill bias on the evolution of skill-specific unemployment and wage rates. Further research should be aimed at understanding in depth the linkages between skill-biased technological change and total factor productivity. 


\section{Annex 1}

Table 9.7 Variables used in the CGE model

\begin{tabular}{l|l}
\hline$X_{A C, t}$ & $\begin{array}{l}\text { Composite production by sector AC in } \\
\text { year t }\end{array}$ \\
\hline$K_{A C, t}$ & Capital stock by sector \\
\hline$L_{A C, t}$ & Aggregate labor bundle \\
\hline$P V A_{A C, t}$ & Value-added price \\
\hline$R_{A C, t}$ & Interest rate \\
\hline$P L_{A C, t}$ & Price of aggregate labor bundle \\
\hline$H S_{A C, t}$ & High-skilled labor bundle \\
\hline$M S_{A C, t}$ & Medium-skilled labor bundle \\
\hline$L S_{A C, t}$ & Low-skilled labor bundle \\
\hline$L D_{A C, f, t}$ & High-skilled labor bundle of type $f$ \\
\hline$L D_{A C, g, t}$ & Medium-skilled labor bundle of type $g$ \\
\hline$L D_{A C, l, t}$ & Low-skilled labor bundle of type $l$ \\
\hline$L D L_{A C, l f, t}$ & Local labor bundle of skill type $l f$ \\
\hline$M I G_{A C, l f, t}$ & Migrant labor of skill type $l f$ \\
\hline$L D L A_{a, l f, t}$ & Local labor of age $a$ and skill type $l f$ \\
\hline$E N R_{c, t}$ & Enrolled by educational cycle \\
\hline$G R A D_{c, t}$ & Graduates by educational cycle \\
\hline$N E W E N R_{e d u, t}$ & Newly enrolled in cycles voc or deg \\
\hline$T O T N E W E N R_{t}$ & Newly enrolled in tertiary education \\
\hline$N E W E N R F I E L D_{l f, t}$ & Newly enrolled in tertiary education \\
\hline$a v f w_{l f, t}$ & Average wage of labor of skill type $l f$ \\
\hline$U r_{l f, t}$ & $\begin{array}{l}\text { Unemployment rate of labor of skill } \\
\text { type } l f\end{array}$ \\
\hline$C A N D I D_{l f, t-n}$ & $\begin{array}{l}\text { Successfully accepted candidates by } \\
\text { labor skill type }\end{array}$ \\
\hline$a v f w m_{l f, t}$ & $\begin{array}{l}\text { Average wage of migrant labor of skill } \\
\text { type } l f\end{array}$ \\
\hline$S M I G_{l f, t}$ & Total migrant supply by skill type \\
\hline$I M M I G_{A C, f, t}$ & $\begin{array}{l}\text { Sectoral demand for migrant labor of } \\
\text { skill type } l f\end{array}$ \\
\hline$w f_{A C, l f, t}$ & $\begin{array}{l}\text { Sectoral wage of local labor of skill } \\
\text { type lf }\end{array}$ \\
\hline$a f w_{l f, t}$ & $\begin{array}{l}\text { Average wage of local labor of skill } \\
\text { type } l f\end{array}$ \\
\hline &
\end{tabular}


Table 9.8 Parameters used in the CGE model

\begin{tabular}{|c|c|}
\hline$A_{A C, t}$ & Labor-augmenting productivity parameter \\
\hline$\alpha_{A C, K}$ & Share parameter of capital \\
\hline$\alpha_{A C, L}$ & Share parameter of labor \\
\hline$\alpha_{A C, H S}$ & Share parameter of high-skilled labor \\
\hline$\alpha_{A C, M S}$ & Share parameter of medium-skilled labor \\
\hline$\alpha_{A C, L S}$ & Share parameter of low-skilled labor \\
\hline$A_{H S, A C, t}$ & High-skilled labor productivity parameter \\
\hline$A_{M S, A C, t}$ & Medium-skilled labor productivity parameter \\
\hline$A_{L S, A C, t}$ & Low-skilled labor productivity parameter \\
\hline$\beta_{f}$ & Share parameter of high-skilled labor type $f$ \\
\hline$\beta_{g}$ & Share parameter of medium-skilled labor type $g$ \\
\hline$\beta_{l}$ & Share parameter of low-skilled labor type $l$ \\
\hline$\alpha_{A C, l o c, l f}$ & Share parameter of local labor \\
\hline$\alpha_{A C, m i g, l f}$ & Share parameter of migrant labor \\
\hline$\alpha_{y, l f}$ & Share parameter of young local labor \\
\hline$\alpha_{n y, l f}$ & Share parameter of older local labor \\
\hline dropout $_{c}$ & Dropout rate by educational cycle \\
\hline enrolled $_{c, t}$ & Enrolled by educational cycle (historical figure used in calculations) \\
\hline entrants $_{t}$ & New entrants by educational cycle (historical figure used in calculations) \\
\hline $\operatorname{grad}_{c, t}$ & Graduates by educational cycle (historical figure used in calculations) \\
\hline $\operatorname{exdip}_{c}$ & Share of graduates pursuing further studies, by cycle \\
\hline transmap $_{c, c 2}$ & Mapping parameter relating different educational cycles \\
\hline$e^{e q u i v_{c, c 2}}$ & $\begin{array}{l}\text { Equivalency parameter denoting cycles which are similar in the educational } \\
\text { hierarchy }\end{array}$ \\
\hline gradrate $_{c}$ & Graduation rate, by cycle \\
\hline$\alpha_{\text {voc }}$ & Share parameter of vocational students \\
\hline$\alpha_{\text {deg }}$ & Share parameter of academic students \\
\hline$\gamma_{f}$ & Share parameter of field of study $f$ in academic degrees \\
\hline$\gamma_{g}$ & Share parameter of field of study $g$ in vocational degrees \\
\hline transage $_{l f}$ & Transition rate between age categories, by skill type \\
\hline edumap $_{c, l f}$ & Mapping parameter between educational cycles and labor skill types \\
\hline inact $_{l f}$ & Inactivity rate by skill type \\
\hline places $_{l f, t}$ & Number of places by field of study (tertiary cycles only) \\
\hline mort $_{l f}$ & Mortality rate by labor skill type \\
\hline retir $_{l f}$ & Retirement rate by labor skill type \\
\hline$w_{\text {dom }} m_{l f, t}$ & Domestic country wage rate by skill type \\
\hline$\beta_{1, l f}$ & Wage curve intercept parameter \\
\hline$\beta_{2, l f}$ & Wage curve elasticity parameter \\
\hline fwdist $_{A C, l f}$ & Exogenous sectoral wage differentials by skill type \\
\hline
\end{tabular}


Table 9.9 Elasticity parameters used in the CGE model

\begin{tabular}{l|l}
\hline$\sigma_{1, A C}$ & $\begin{array}{l}\text { Elasticity of substitution between aggregate labor and } \\
\text { aggregate capital }\end{array}$ \\
\hline$\sigma_{2, A C}$ & $\begin{array}{l}\text { Elasticity of substitution between high-skilled, medium-skilled, } \\
\text { and low-skilled labor }\end{array}$ \\
\hline$\sigma_{3, A C}$ & Elasticity of substitution between high-skilled labor bundles \\
\hline$\sigma_{4, A C}$ & $\begin{array}{l}\text { Elasticity of substitution between medium-skilled labor } \\
\text { bundles }\end{array}$ \\
\hline$\sigma_{5, A C}$ & Elasticity of substitution between low-skilled labor bundles \\
\hline$\sigma_{6, A C, l f}$ & Elasticity of substitution between migrant and local labor \\
\hline$\sigma_{7, A C}$ & Elasticity of substitution between younger and older labor \\
\hline$\sigma_{8, A C, l f}$ & Elasticity of transformation of migrant supply \\
\hline$\sigma_{9, l f}$ & Elasticity of transformation of migrants between sectors \\
\hline$\sigma_{10, l f}$ & $\begin{array}{l}\text { Elasticity of transformation between vocational and academic } \\
\text { studies }\end{array}$ \\
\hline$\sigma_{11, l f}$ & Elasticity of transformation between vocational degrees \\
\hline$\sigma_{12, l f}$ & Elasticity of transformation between academic degrees \\
\hline
\end{tabular}

Table 9.10 CET equations used to derive educational demands

The maximization problem at hand is

$$
\begin{aligned}
& \operatorname{Max}\left(\sum_{e d u}\left[a v f w_{e d u, t} \times N E W E N R_{e d u}\right]\right) \\
& \quad \text { subject to TOTNEWENR } R_{t}=\left[\alpha_{v o c} \times N E W E N R_{v o c, t}^{\rho_{10}}+\alpha_{\text {deg }} \times N E W E N R_{\text {deg }, t}^{\rho_{10}}\right]^{\frac{1}{\rho_{10}}}
\end{aligned}
$$

For the choice of field of study, the following CET functions were used:

For general higher education:

$$
\begin{aligned}
& \operatorname{Max}\left(\sum_{f}\left[a v f w_{f, t} \times N E W E N R F I E L D_{f, t}\right]\right) \\
& \text { subject to } N E W E N R_{\mathrm{deg}, t}=\left[\gamma_{f} \times \sum_{f} N E W E N R F I E L D_{f, t}^{\rho_{12}}\right]^{\frac{1}{\rho_{12}}}
\end{aligned}
$$

For vocational higher education:

$$
\begin{aligned}
& \operatorname{Max}\left(\sum_{g}\left[a v f w_{g, t} \times N E W E N R F I E L D_{g, t}\right]\right) \\
& \text { subject to } \quad N E W E N R_{v o c, t}=\left[\gamma_{g} \times \sum_{g} N E W E N R F I E L D_{g, t}^{\rho_{12}}\right]^{\frac{1}{\rho_{12}}}
\end{aligned}
$$


Table 9.11 Evolution of industry labor shares and proportion of skilled labor by industry, 1990-2011

\begin{tabular}{l|r|r}
\hline Industry & $\begin{array}{l}\Delta(\text { labor share }) \\
(\%)\end{array}$ & $\Delta($ skills share $)(\%)$ \\
\hline Agriculture & -13.6 & 2.1 \\
\hline Oil and gas & 0.0 & 27.0 \\
\hline Manufacturing food, beverages, tobacco & -0.2 & 8.9 \\
\hline Manufacturing textile & -2.3 & 7.0 \\
\hline Manufacturing wood & -0.4 & 2.7 \\
\hline Manufacturing paper and furniture & 0.4 & 10.7 \\
\hline Manufacturing chemicals rubber & 0.4 & 16.2 \\
\hline Metals, machinery, equipment NEC & -0.1 & 12.3 \\
\hline Electronics and electrical & 4.1 & 16.5 \\
\hline Manufacturing and transport equipment & 0.4 & 16.0 \\
\hline Utilities & -1.5 & 23.2 \\
\hline Construction & 2.9 & 11.2 \\
\hline Wholesale and retail & 2.1 & 10.3 \\
\hline Accommodation and restaurants & 2.1 & 6.3 \\
\hline Logistics & 1.4 & 11.7 \\
\hline Post and telecom & 0.9 & 59.6 \\
\hline Finance & 0.7 & 33.7 \\
\hline Real estate & 0.2 & 30.6 \\
\hline Business services & 3.8 & 15.8 \\
\hline Education & 0.7 & 20.9 \\
\hline Health & 0.9 & 44.0 \\
\hline Other services & -2.3 & 6.8 \\
\hline Public administration & -0.6 & 23.0 \\
\hline Sorce Auhs cal &
\end{tabular}

Source: Authors' calculations from the 1990 and 2011 LFS. 


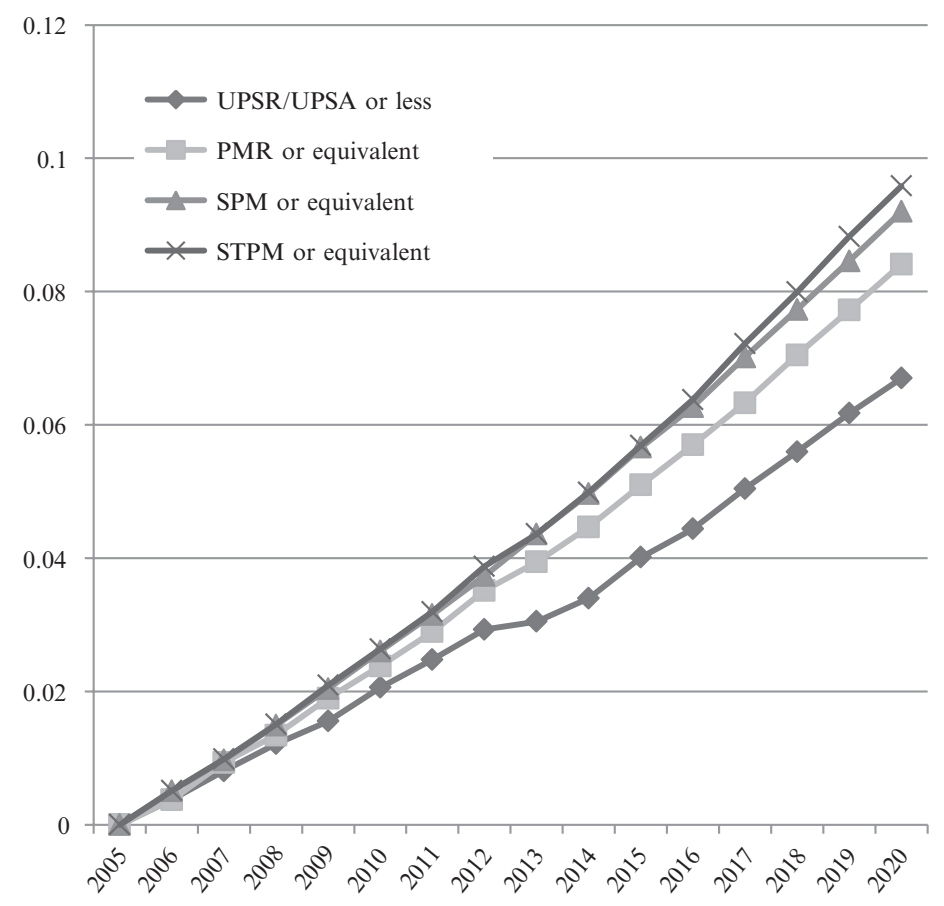

Fig. 9.6 Evolution of wages of low-skilled Malaysians without SBTC. (Source: Authors' calculations using results from the model) 


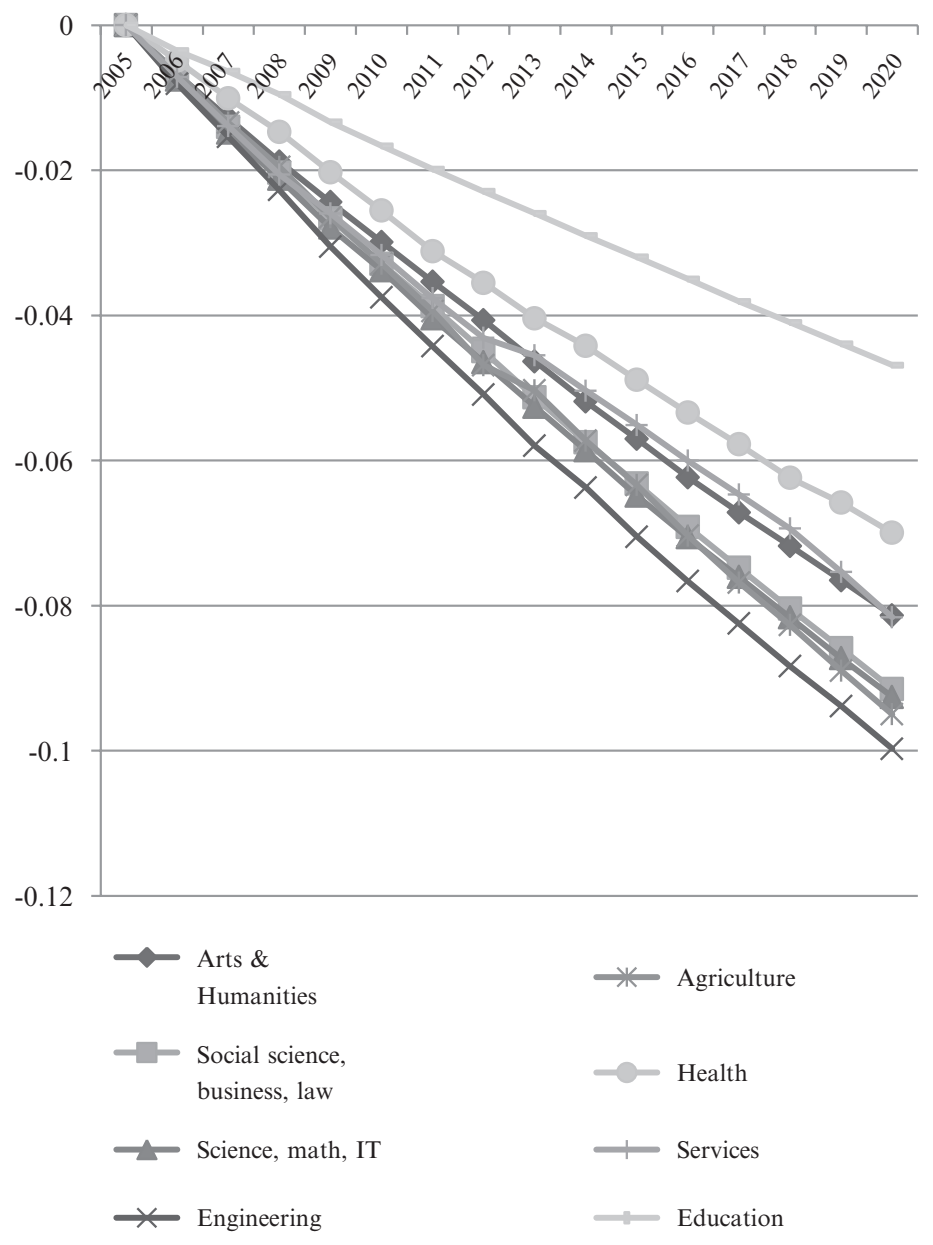

Fig. 9.7 Evolution of wages of diploma holders without SBTC. (Source: Authors' calculations using results from the model) 


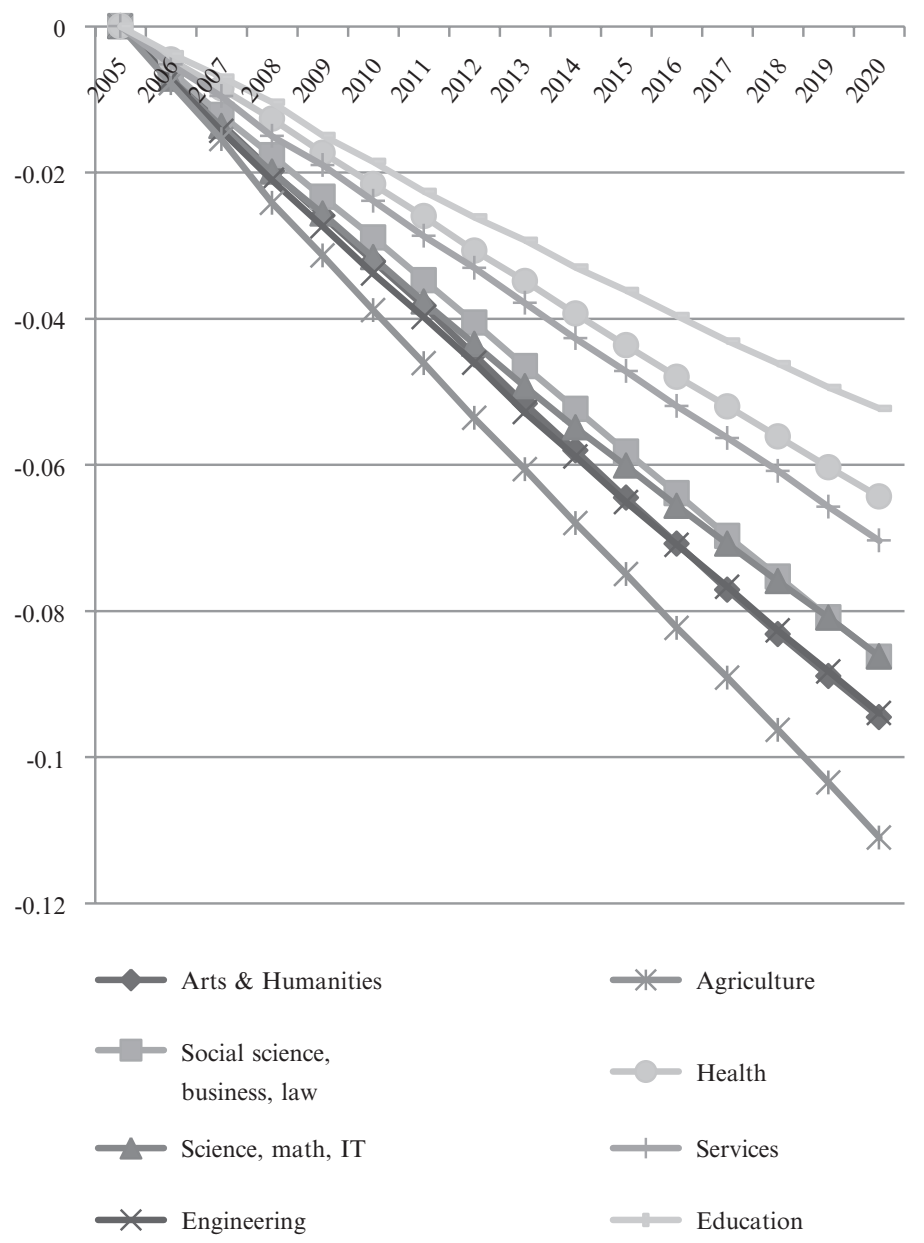

Fig. 9.8 Evolution of wages of degree holders without SBTC. (Source: Authors' calculations using results from the model) 


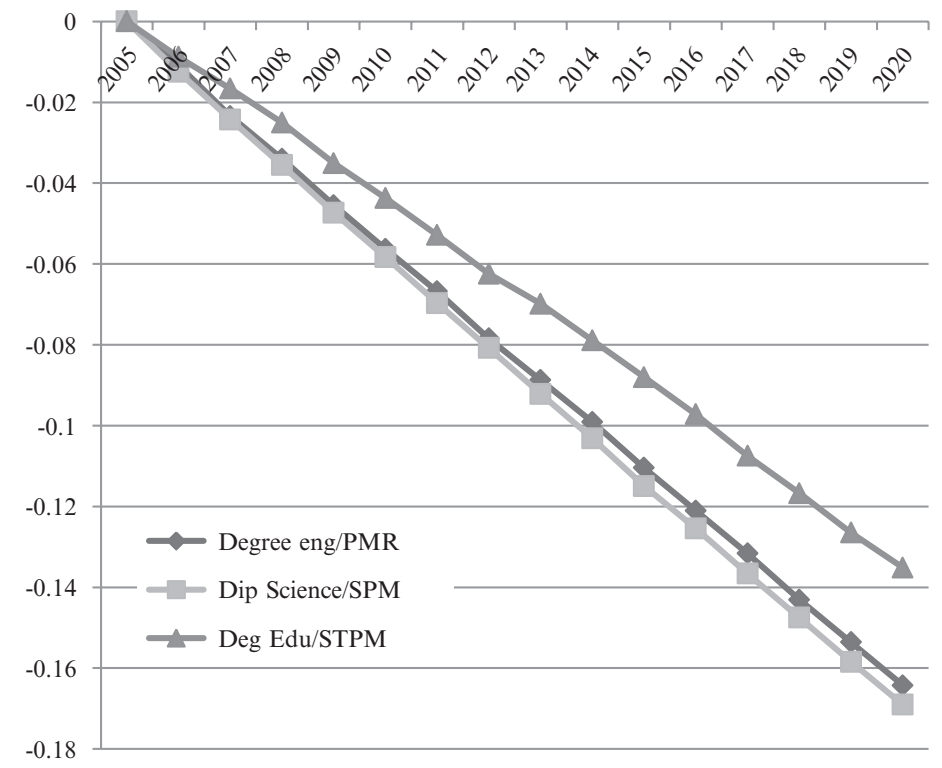

Fig. 9.9 Evolution of selected wage differentials without SBTC. (Source: Authors' calculations using results from the model) 


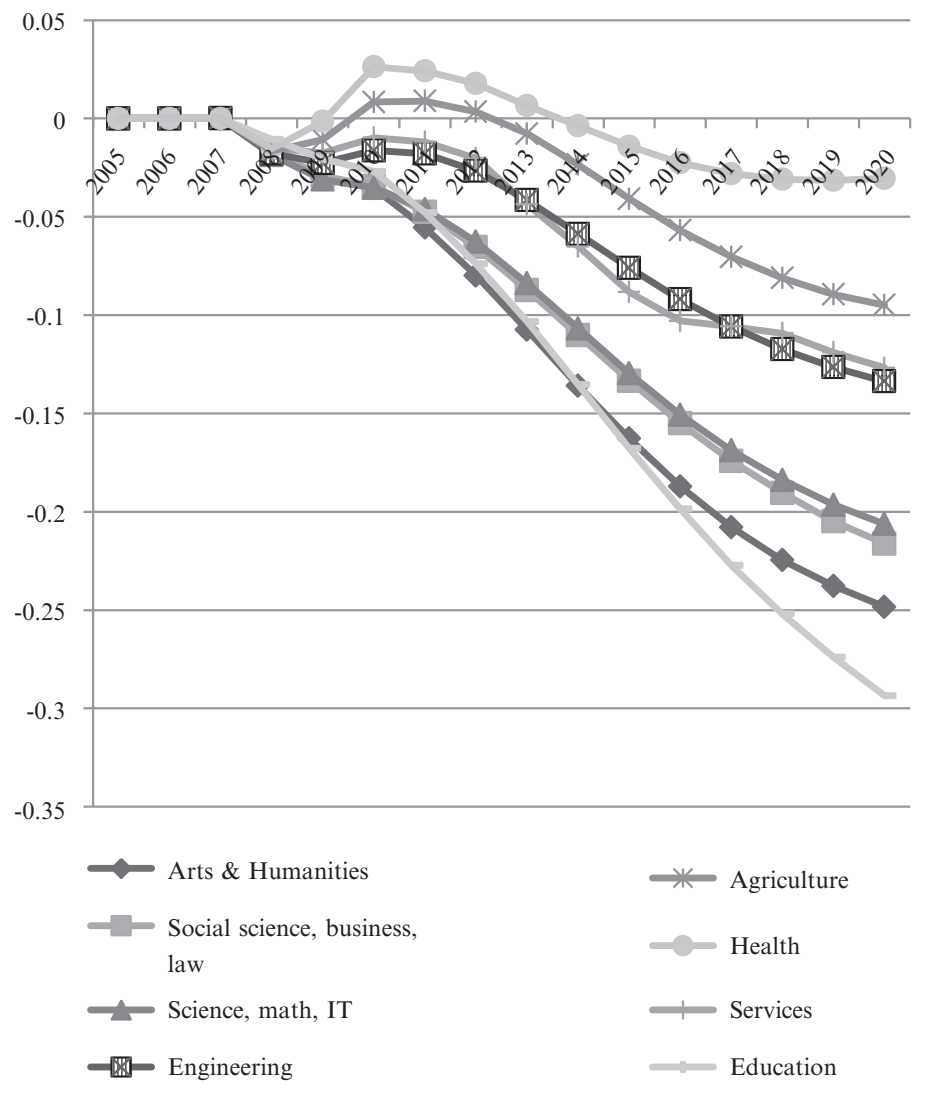

Fig. 9.10 Evolution of unemployment of diploma-holding wage earners with rationing. (Source: Authors' calculations using results from the model) 


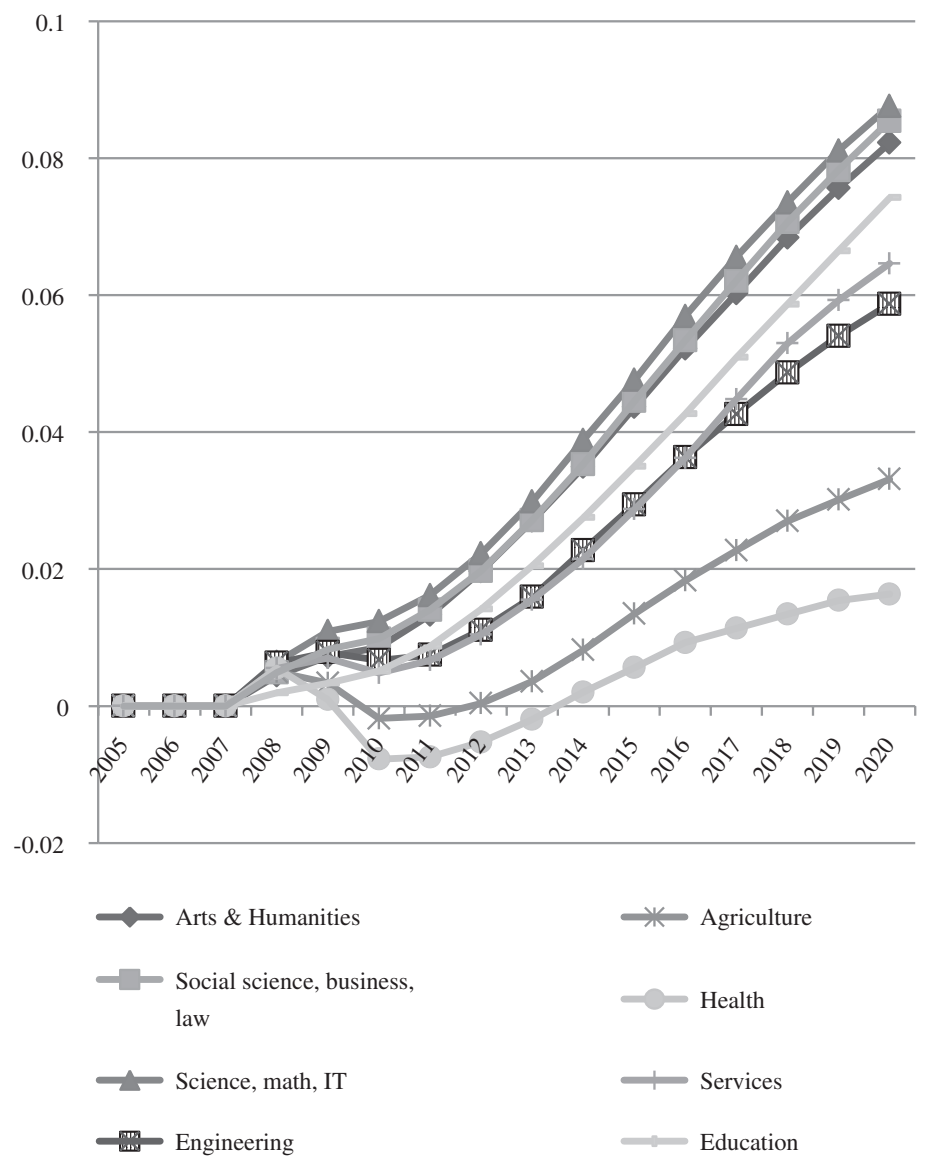

Fig. 9.11 Evolution of wages of diploma holders with rationing. (Source: Authors' calculations using results from the model) 


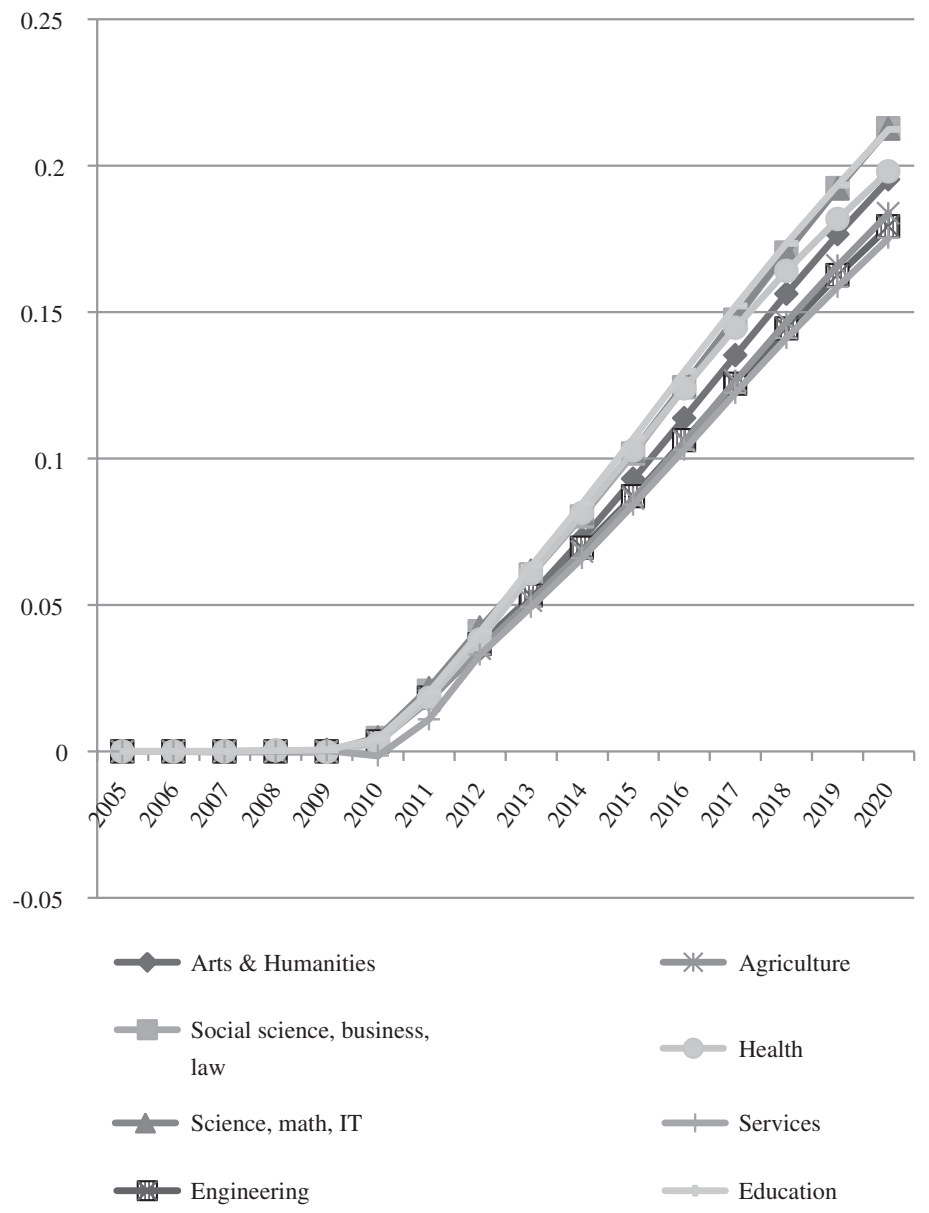

Fig. 9.12 Evolution of wages of degree holders with rationing. (Source: Authors' calculations using results from the model) 


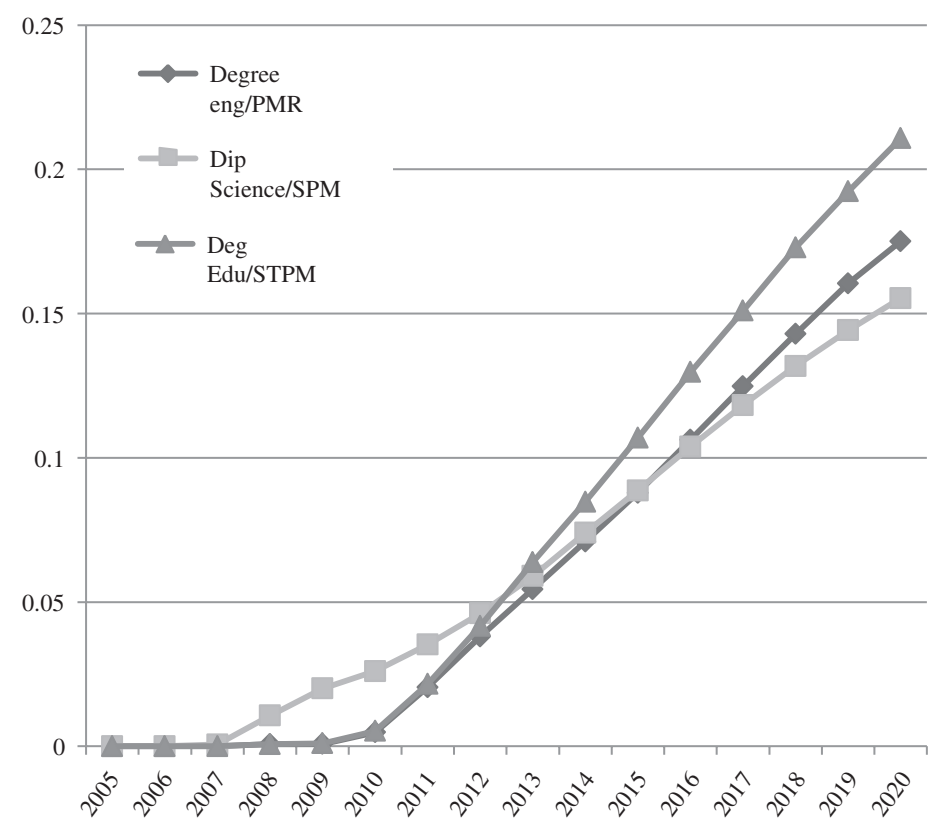

Fig. 9.13 Evolution of selected wage differentials with rationing. (Source: Authors' calculations using results from the model)

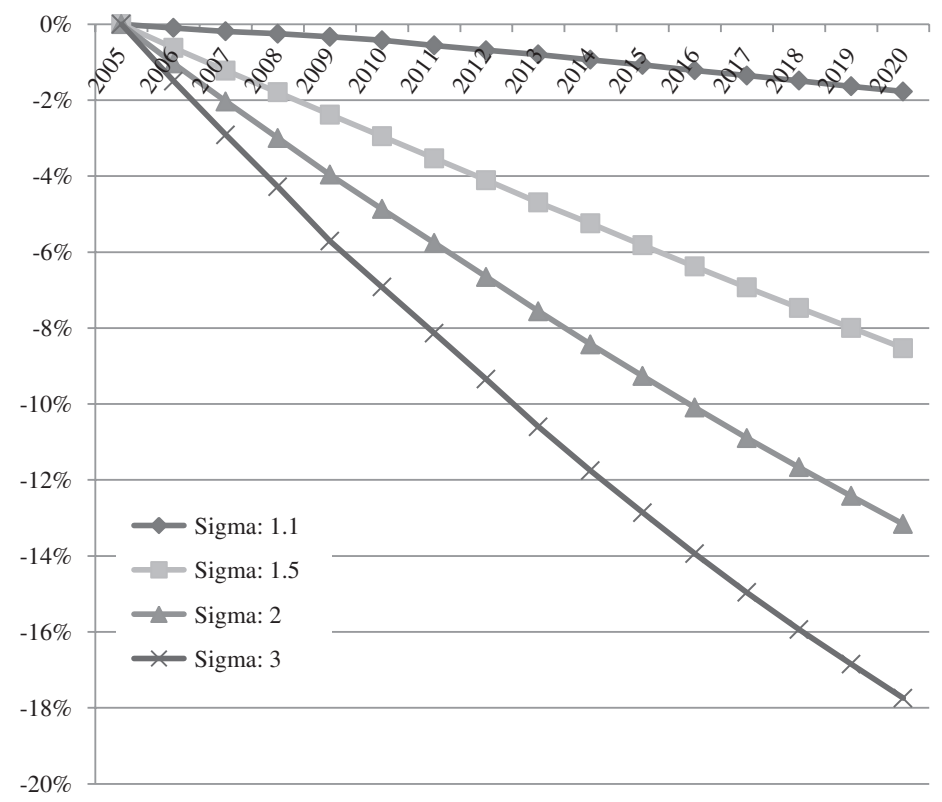

Fig. 9.14 Evolution of degree holders' wages without SBTC (4\%) for various elasticities of substitution. (Source: Authors' calculations using results from the model) 


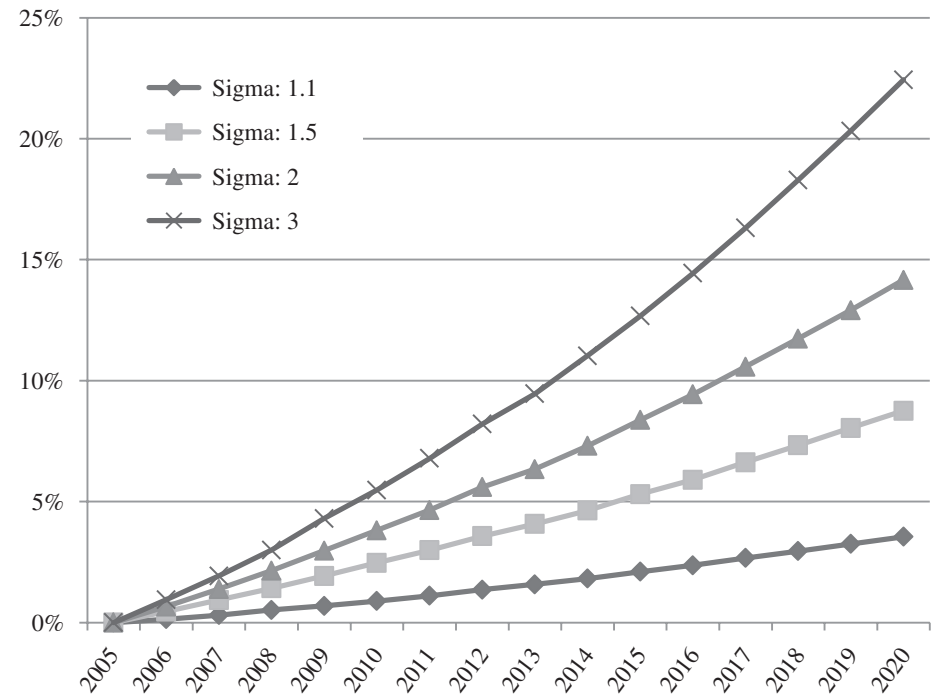

Fig. 9.15 Evolution of wages of less-skilled workers without SBTC (4\%) for various elasticities of substitution. (Source: Authors' calculations using results from the model)

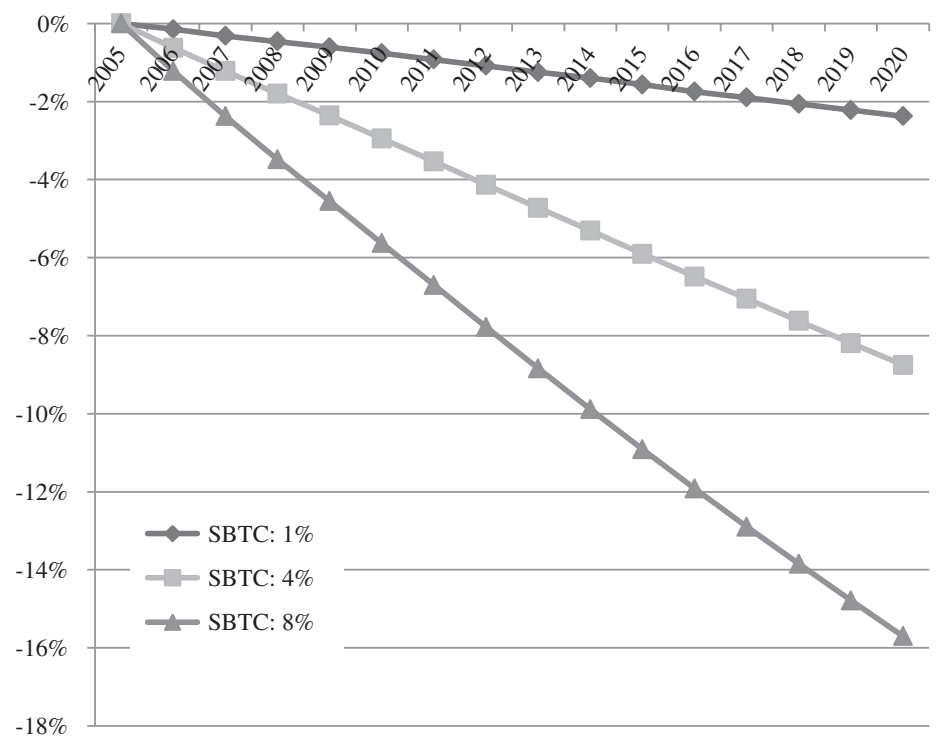

Fig. 9.16 Evolution of degree holders' wages for various levels of SBTC (Sigma: 1.5). (Source: Authors' calculations using results from the model) 


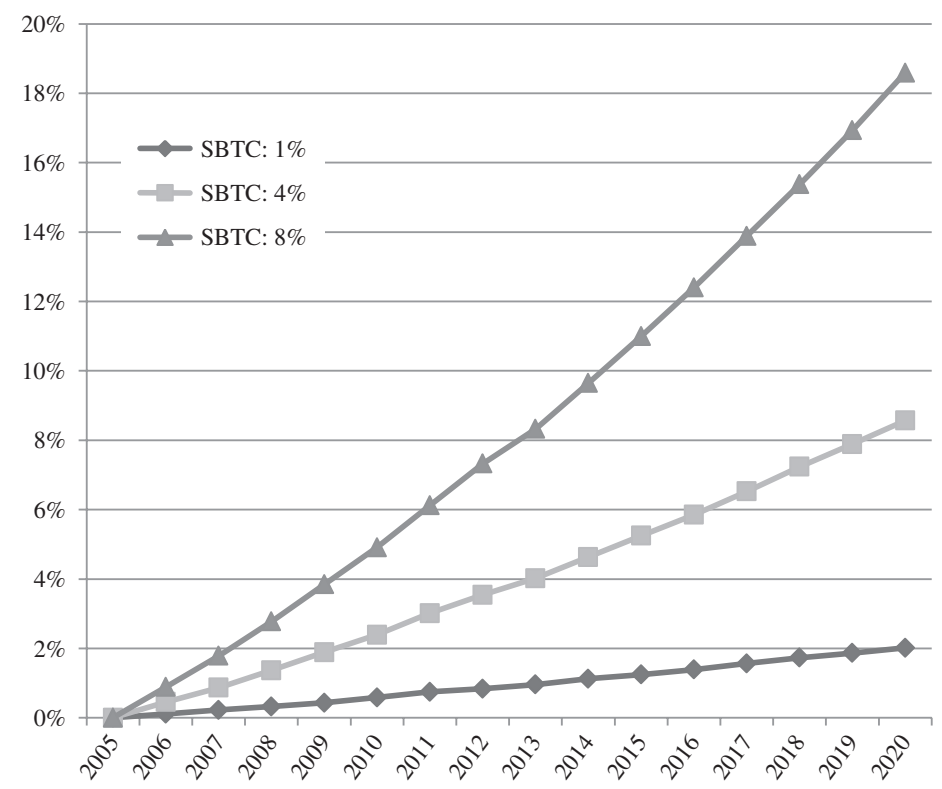

Fig. 9.17 Evolution of wages of less-skilled workers for various levels of SBTC (Sigma: 1.5). (Source: Authors' calculations using results from the model)

\section{References}

Acemoglu, D. (1998). Why do new technologies complement skills? Directed technical change and wage inequality. Quarterly Journal of Economics, 113, 1055-1089.

Acemoglu, D. (2002). Directed technical change. Review of Economic Studies, 69(4), 781-809.

Acemoglu, D., \& Angrist, J. (1999). How large are the social returns to education? Evidence from compulsory schooling laws. Technical report, National bureau of economic research.

Acemoglu, D., \& Autor, D. (2011). Skills, tasks and technologies: Implications for employment and earnings. Handbook of labor economics, 4, 1043-1171.

Autor, D. H., Katz, L. F., \& Krueger, A. B. (1998). Computing inequality: Have computers changed the labor market? The Quarterly Journal of Economics, 113(4), 1169-1213.

Beffy, M., Fougere, D., \& Maurel, A. (2012). Choosing the field of study in postsecondary education: Do expected earnings matter? Review of Economics and Statistics, 94(1), 334-347.

Berman, E., Bound, J., \& Machin, S. (1998). Implications of skill-biased technological change: International evidence. The Quarterly Journal of Economics, 113(4), 1245-1279.

Berman, E., \& Machin, S. (2000). Skill-based technology transfer around the world. Oxford Review of Economic Policy, 16(3), 12-22.

Blaug, M. (1967). Approaches to educational planning. The Economic Journal, 77, 262-287.

Blaug, M., \& Ahamad, B. (1974). The practice of manpower forecasting. Amsterdam: Elsevier. 
Bogliacino, F., \& Lucchese, M. (2015). Endogenous skill biased technical change: testing for demand pull effect. Industrial and corporate change, dtv010.

Canton, E., \& de Jong, F. (2005). The demand for higher education in The Netherlands, 19501999. Economics of Education Review, 24(6), 651-663.

Card, D., \& Lemieux, T. (2001). Can falling supply explain the rising return to college for younger men? A cohort-based analysis. The Quarterly Journal of Economics, 116(2), 705-746.

Caselli, F., \& Coleman, W. J. (2006). The world technology frontier. American Economic Review, 96(3), 499-522.

Chung, T. P. (2003). Returns to education: Updates for Malaysia. Applied Economics Letters, 10(13), 837-841.

Conte, A., \& Vivarelli, M. (2011). Imported skill-biased technological change in developing countries. The Developing Economies, 49(1), 36-65.

Duchesne, I., \& Nonneman, W. (1998). The demand for higher education in Belgium. Economics of Education Review, 17(2), 211-218.

Eaton, J., \& Kortum, S. (2001). Trade in capital goods. European Economic Review, 45(7), $1195-1235$.

Freeman, J. A., \& Hirsch, B. T. (2008). College majors and the knowledge content of jobs. Economics of Education Review, 27(5), 517-535.

Glytsos, N. P. (1990). Modelling future higher education-labor market imbalances: A multiscenario approach. Economics of Education Review, 9(1), 1-23.

Goldin, C., \& Katz, L. F. (1998). The origins of technology-skill complementarity. The Quarterly Journal of Economics, 113(3), 693-732.

Guan, L. H. (2012). Racial citizenship and higher education in Malaysia. In E. T. Gomez \& J. Saravanamuttu (Eds.), The new economic policy in Malaysia. Singapore: NUS Press.

Kabbani, N., \& Kothari, E. (2005). Youth employment in the MENA region: A situational assessment (SP Discussion Paper 534). Washington, DC: World Bank.

Katz, L. F., \& Murphy, K. J. (1992). Changes in relative wages, 1963-1987: Supply and demand factors. Quarterly Journal of Economics, 107(1), 35-78.

Kenayathulla, H. B. (2013). Higher levels of education for higher private returns: New evidence from Malaysia. International Journal of Educational Development, 33, 380-393.

Machin, S., \& Reenen, J. V. (1998). Technology and changes in skill structure: Evidence from seven OECD countries. The Quarterly Journal of Economics, 113(4), 1215-1244.

Marouani, M. A. (2010). More jobs for university graduates: Some policy options for Tunisia. Applied Economics Letters, 17(10), 933-937.

Marouani, M. A., \& Robalino, D. A. (2012). Assessing interactions among education, social insurance and labor market policies in Morocco. Applied Economics, 44(24), 3149-3167.

McIntosh, S. (2001). The demand for post-compulsory education in four European countries. Education Economics, 9(1), 69-90.

Montmarquette, C., Cannings, K., \& Mahseredjian, S. (2002). How do young people choose college majors? Economics of Education Review, 21(6), 543-556.

Ozden, C., \& Wagner, M. C. (2014). Immigrant versus natives? Displacement and job creation. Displacement and Job Creation (June 1, 2014). World Bank Policy Research Working Paper (6900).

Pritchett, L. (1996). Where has all the education gone?(1581). Technical report, The World Bank. 
Sanders, M., \& ter Weel, B. (2000). Skill-biased technical change theoretical concepts, empirical problems and a survey of the evidence (00-8) (Technical report). DRUID, Copenhagen Business School, Department of Industrial Economics and Strategy/Aalborg University, Department of Business Studies.

World Bank (Forthcoming). Developing skills for innovation and high income economy in Malaysia.

World Bank. (2008). The road not traveled: Education reform in the Middle East and Africa. Washington, DC: World Bank.

The views expressed in this publication are those of the authors and do not necessarily reflect the views and policies of the Asian Development Bank (ADB) or its Board of Governors or the governments they represent.

ADB does not guarantee the accuracy of the data included in this publication and accepts no responsibility for any consequence of their use. The mention of specific companies or products of manufacturers does not imply that they are endorsed or recommended by ADB in preference to others of a similar nature that are not mentioned.

By making any designation of or reference to a particular territory or geographic area, or by using the term "country" in this document, $\mathrm{ADB}$ does not intend to make any judgments as to the legal or other status of any territory or area.

Open Access This work is available under the Creative Commons Attribution-NonCommercial 3.0 IGO license (CC BY-NC 3.0 IGO) http://creativecommons.org/licenses/by-nc/3.0/igo/. By using the content of this publication, you agree to be bound by the terms of this license. For attribution and permissions, please read the provisions and terms of use at https://www.adb.org/ terms-use\#openaccess.

This CC license does not apply to non-ADB copyright materials in this publication. If the material is attributed to another source, please contact the copyright owner or publisher of that source for permission to reproduce it. ADB cannot be held liable for any claims that arise as a result of your use of the material.

Please contact pubsmarketing@adb.org if you have questions or comments with respect to content, or if you wish to obtain copyright permission for your intended use that does not fall within these terms, or for permission to use the ADB logo.

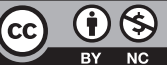

